\title{
SPATIAL DYNAMICS OF PELAGIC FISH AGGREGATION IN THE JAVA SEA BASED ON HYDRO-ACOUSTICS
}

\begin{abstract}
Bambang Sadhotomo"
ABSTRACT

This study was based on a concept called acoustic population estimation. This is defined as a population of echoes which is based on the hyphothesis that a synthesis of biological and behavioural characteristics of the species (within a community) characterizes the community (Gerlotto \& Marchal, 1987). The acoustic data representing the acoustic population contains a set of information that can be used to represent the natural population. This study describes the community and behaviour of pelagic populations in the Java Sea. The acoustic data were collected during two large scale cruises in October 1993 and February 1994. The surveys represented the northwest and southeast monsoon periods. Acoustic shoal feature were derived from the acoustic data by means of MOVIES-B software. Graphical presentation and mapping were performed to represent the interrelation of shape and position dimension variables of the shoals. Totals of 350 and 143 shoals were obtained from October 1993 and February 1994 cruises respectively. Based on these variables analyses can be performed. Global observations on the shoal types reveal a possible zonation being generated by similarity of certain characters. Zones of different types of aggregation can be recognized in term of their spatial distribution, with each zone representing specific agregations reflecting fish of particular communities. The internal migration of fish within the Java Sea may endanger stratification of the pelagic community into three parts during the two seasons, i.e. western, central and eastern zones.
\end{abstract}

KEYWORDS: $\quad$ spatial distribution, acoustic, pelagic, shoal, stratification, Java Sea

\section{INTRODUCTION}

In marine ecosystems, most of fish species are concentrated in response to particular features of environment (such as current, shelf edge, transparency etc.) by forming structures with specification mainly depending on species and age, or a combination of these. Spatial dependence or continuity distribution such as a tendency for organisms to form patchiness, clumped in some areas, and random or sparse in other areas, is a common phenomenon in marine ecology (Maravelias et ai., 1996). However, in marine ecosystems the dynamics of patchiness have proven less amenable to direct observation being limited by ability to observe directly the processes underlying patch dynamic in the sea (Greene et al., 1994).

In this case, natural movement of pelagic fish in three-dimensional space and hydrological environment of the sea are parts of the problems (this is not in case in terrestrial systems).

The particular form of this structure is called as shoal or school, (Swartzman, 1997) understanding this factual phenomenon in relation to environmental factors being triggered by seasonal variability would provide auxiliary information for the study of spatial distribution. The possibility of an impact of shoal behaviour on acoustic biomass estimates is most likely (Fréon et al., 1993). From another point of view, constraints in breaking down into species of estimated biomass have encouraged scientists to attempt to classify fish shoals according to species. This could be a crucial problem as the pelagic fish communities are composed of several species (e.g. the catch composition from purse seines in the Java Sea indicate that at least 9 species may be present in samples). Several acoustic methods have been developed for species identification purposes of the sparse and aggregated shoals. Simmonds et al. (1992) give a comprenhensive review on the classification of these methods

Most of the identification methods used in these studies are based on the spatial structure, but have limitations, i.e. the fish may not stay in a space in a random manner (Fréon, et al., 1990). In applying this to tropical waters, the fishing-based species identifications are not clearly represented by acoustic characteristics. In order to overcome this problem, an indirect method which relates to the general characteristics of the pelagic community can be used. If the global variation becomes the main consideration, a concept of the "acoustic population" (Geriotto \& Marchal, 1987) can be used to describe the commu-

\footnotetext{
"Researcher at the Research Institute for Marine Fisheries, Muara Baru
} 
nity and behaviour of the pelagic populations in the Java Sea. Acoustic population is defined as a population of echoes. It is based on the hyphothesis that a synthesis of the biological and behavioural characterictics of the species (within the community) characterizes the community; therefore community features may be described by acoustic data representing the acoustic population (Gerlotto, 1993). The basic principle is that the acoustic population contains a set of information that can be used to described the natural population.

However, most of the natural characters do not have a direct causal relation to one or more of acoustic characters, withg perhaps only the average size of the fish in a natural population specifically reflected as target strength (one of the acoustic population characters). The main dependence factors determining the acoustic population features are the anatomy, physiology, fish orientation and position as well as their distribution. Detailed explanations of their relations to acoustic echoes have been discussed exhaustively elsewhere (Foote, 1979; Foote \& Ona, 1985a; 1985b; Foote 1980a;1980b; Fréon et al., 1996; 1993).

In this study, the main objective was not to identify the species or group of species, but to map the community features while emphasizing spatial stratification based on the average value of the acoustic characters. Identification is therefore based on the strata. This is analogous to an approach commonly used in the classic ecological appraisal based on community structure, e.g. certain level of disturbance of the whole population may be reflected by changes in the community structure (Sainsbury, 1982). In this case, the general concept of diversity may be used to identify the community structure (Pielou, 1977).

\section{METODOLOGY}

\section{General Theory}

This study deals only with the utilisation of a certain part of the acoustic data collected during acoustic cruises of RN Bawal Putih. Two cruises were chosen from the 16 cruises made during the Pelfish Project, namely cruises number 34 and 41 , which were carried out on October 1993 and February 1994, cov. ering most of central and eastern parts of the Java Sea. These cruises represent the conditions during the southeast and northwest monsoon (Figure 1). Integration data were recorded during the cruises, and saved in the format of INES-MOVIES. The information content of the data are the date, time, position and digitized signal received by echo-sounder.
The broad spatial area coverage and the periods of the two cruises, allow study of the behaviour of shoals relative to the environment as influenced by monsoonal climate, based on the acoustics data collection. The acoustic technique is valuable as a tool for describing ecological phenomena as well as for direct estimation of fish stock assessment. In this study, it is performed in two fashions. Firstly, for describing the relationship between partition of shoals, their parameters (shape, density) and environment condition; and secondly to evaluate their relations to size partition in the Java Sea. Evaluation was focused on the variability of spatial distribution of the shoal structure and comparison of the characters from different subareas and seasons. The use of the acoustic method was mostly based on the treatment of data produced by an echo-integration technique applied during the cruises.

In our case, we assumed that the acoustic characters were random variables generated from natural populations, regardless of any function or process from "natural population space" to "acoustic population space". Aggregation or shoaling can be regarded as common phenomenon for most of the pelagic species, but how far the characteristics of "acoustic shoal" represent those of natural shoals is unknown. In the context of the acoustic population concept, the pattern of acoustic shoal dimensions can be assumed to represent the general characteristics of the natura! shoals. The MOVIES-B method may be used to identify characteristics of shoals based on several descriptors without having to verify shoal composition using catch data. The important step in applying this concept is to define appropriate variables that can be used to classify the shoal data concerning the spatial structure of the acoustic shoal. In this study, we do not perform species identification, due to the nonavailaibility of fishing composition data corresponding to the identified shoals. This study emphasizes the following points: (a) a general description of the spatial distribution, (b) the structure of shoal dimen. sion, (c) a general classification and zonation based on the similarity of the dimension variables and (d) the relationships between classes of descriptors

The definition emphasizes the spatial characteris tics and focuses on the orientation and the movement of pelagic fish in distribution and space in relation to their life history in the Java Sea. Behaviour of aggregation is assumed to be related to their response to environment conditions. In term of acoustic detection, a shoal is defined as a set of samples which forms an echogram feature (Weill et al., 1993). The behaviour of the shoal in the acoustic detection will be a characteristic feature recognized by the acoustics system used. Shoal by shoal integration was also per- 
Cruise 34 (October 1993)

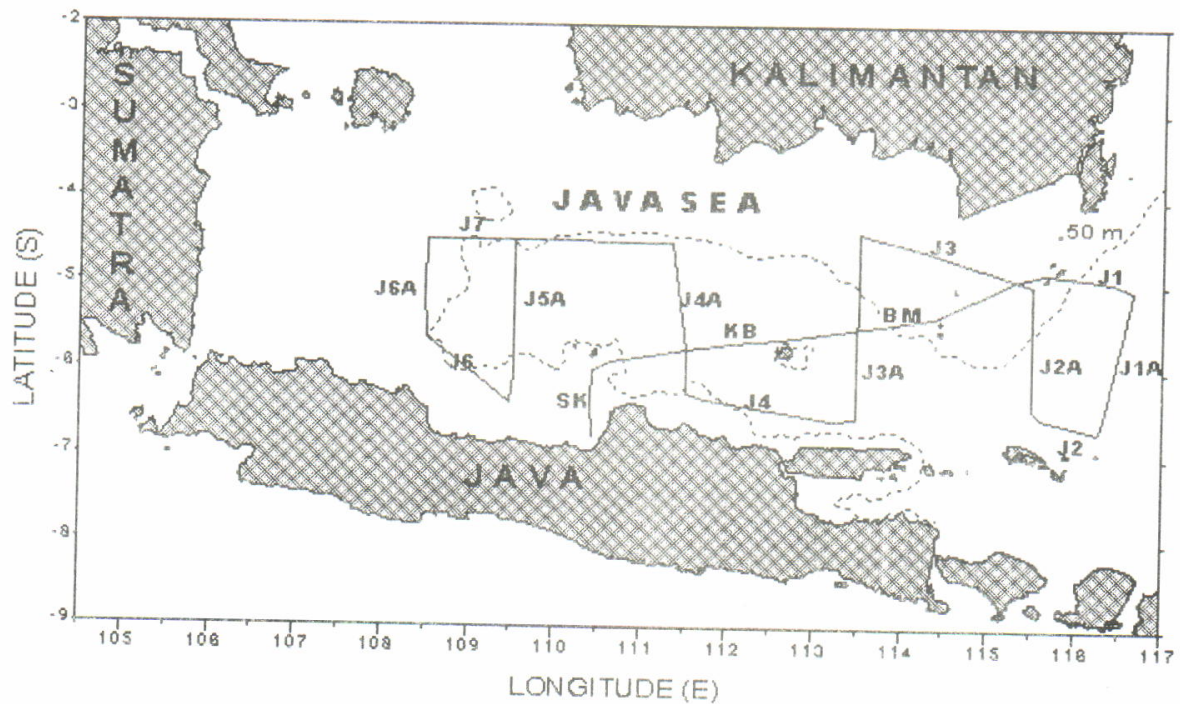

Cruise 41 (February 1994)

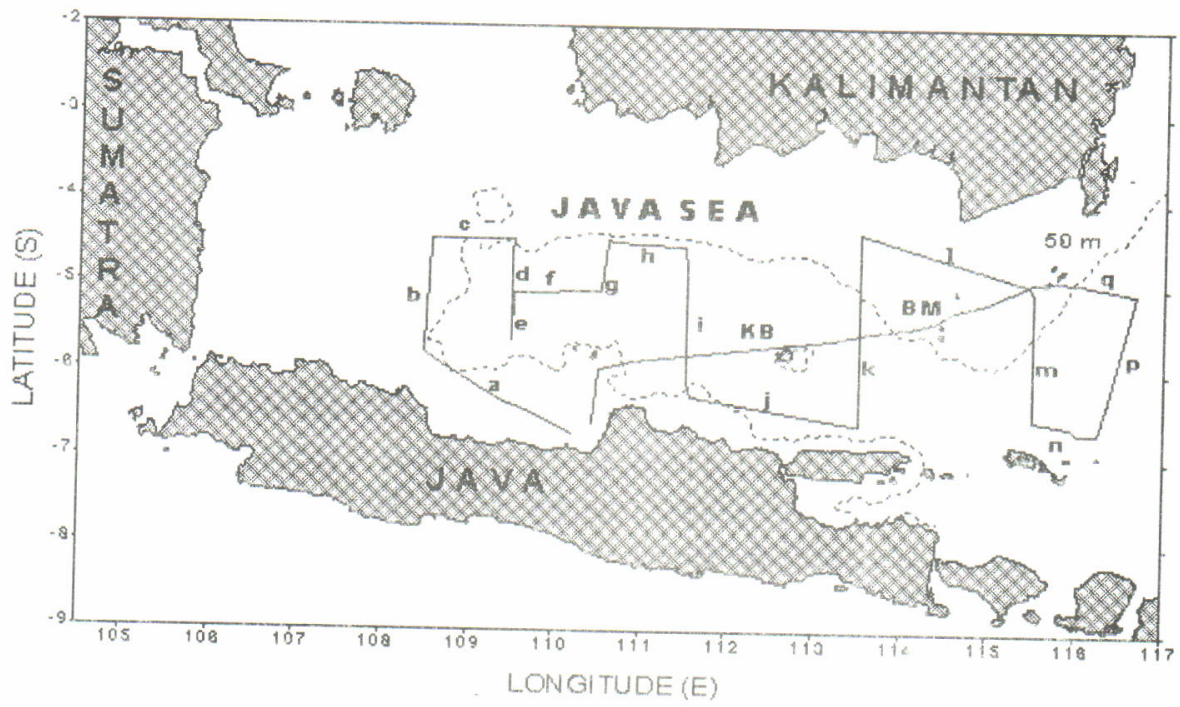

Figure 1. Acoustic cruise tracks made during two seasons

formed to describe the structure of the shoal through energetic, morphologic, spatial and temporal descriptors. In the case of identification of the detection, a newer technique allowing automatic discrimination of the shoal acoustic response from other echoes is available in the software MOVIES-B

A Biosonic dual beam vertical echo-sounder operating at $120 \mathrm{kHz}$ frequency was utilized. Some information on operational issues (i.e. speed of the ship, heading and her position) were integrated through INES-MOVIES and Biosonic finterfaces. The INESMOVIES data processing system was designed by IFREMER to perform echo-integration of vertical echo sounding (Diner, 1995). The data acquisition of this system can be described as Figure 2. However, the use of this technique is limited by the fact that the vertical echo-sounder measures only the height and the length of a shoal passing under the vessel. This provides good vertical resolution but horizontally gives a less accurate measure. For this reason, the circuar shape of the shoal is assumed (Scalabrin \& Massé, 1993)

Weill et al (1993) described the algorithm of this software for defining a shoal from echogram features based on "contiguity of sample criteria". In a vertical sense, it is contiguity along the same "ping" and hori- 


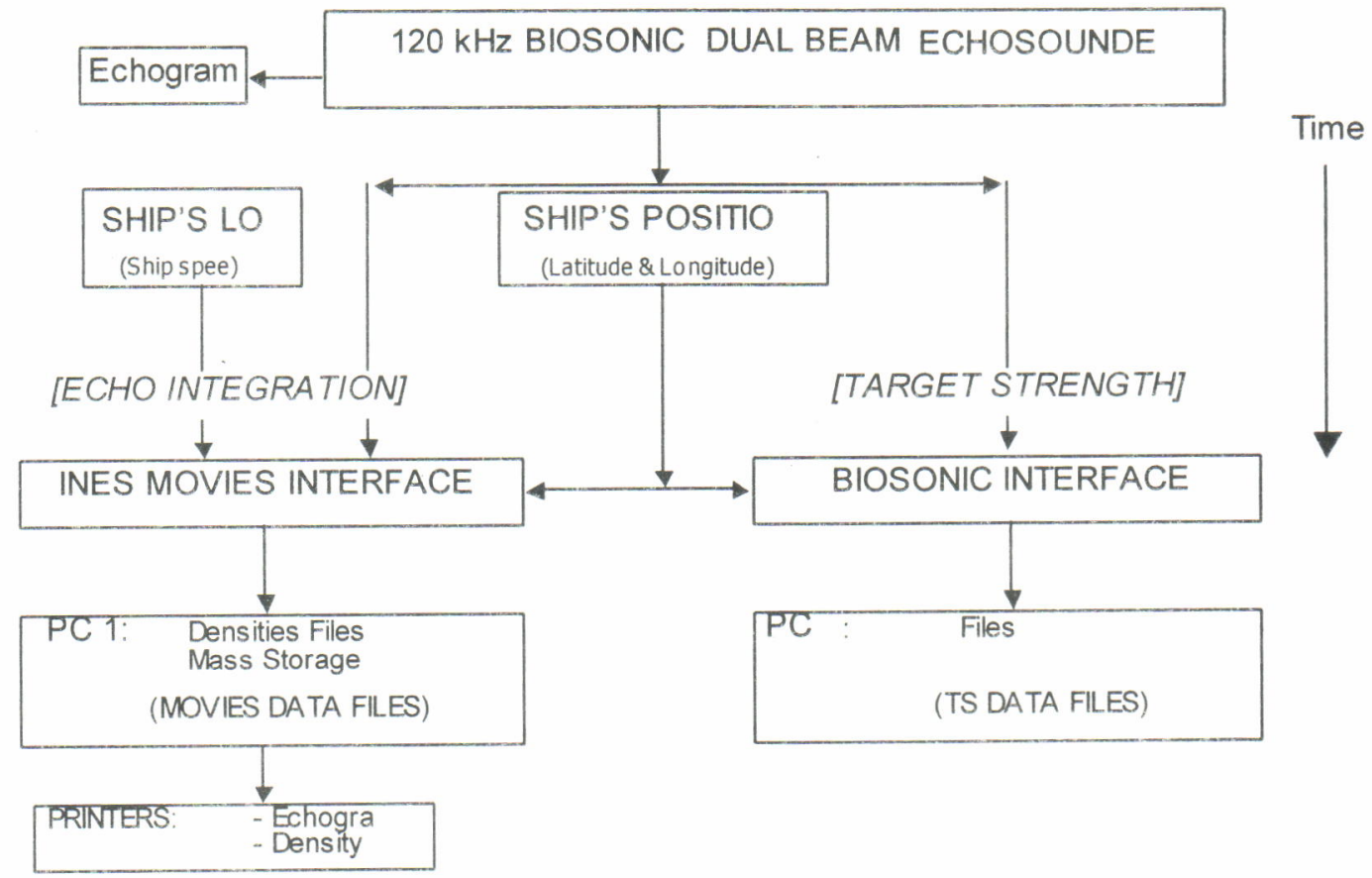

Figure 2. System of data acquisition used during the cruise of R/v Bawal Putih (Petit et al., 1995)

zontally, it is from one ping back to the previous one (Figures 3 and 4). Vertical segments are defined for each ping, and are composed by the sample having an amplitude value above the echo-integration threshold defined manually by the user. The criteria of vertical contiguity is that each segment has a vertical contiguous sample of less than half the pulse duration. It means that a sample of more than $\mathbf{0 . 5}$ t.c. $\mathrm{h}$ will not be accepted as a shoal (where $t=$ pulse duration $(\mathrm{s}), \mathbf{c}=$ speed of sound in water $(\mathrm{m} / \mathrm{s})$ and $\mathrm{h}=$ the vertical resolution representing the number of vertical samples per meter)

Horizontal contiguity will be verified by a search being made to find at least one sample having the same depth as one segment sample values from the previous ping. Contiguous numbers of segments are considered as the same shoal detection, and the detection of a shoal will terminate if the number of samples is not increased after a new ping.

These criteria may result in a shoal (an acoustic detection shoal) that is not really a natural one. It may be part of natural big shoal detected as cluster of shoals. A definition of a natural shoal of Radakov $(1973)$ is that a shoal is an active aggregation which may frequently change its shape as a response to external stimuli. A discontinuity may exist within a natural shoal and it may be detected as separated shoals by the algorithm of MOVIES-B. Selected descriptors are listed in the Table 1.

\section{Adjustment of threshold}

Experimental trials had been performed using several settings for eliminating the bottom and surface noises. The best setting then was decided by considering a logical interpretation on the echogram feature. Some of these were used as input parameters for playing back the data by using the MOVIES-B software. We concluded that for the data and system of apparatus used, the most reasonable thresholds appropriate for a shoal would be:

- Color palette > 3\%

- Minimum back-scattered energy $>100$ mv $^{2}$

- Minimum number of pings $>3$

- Minimum number of samples $>30$

\section{RESULTS AND DISCUSSION}

\section{Distribution of shoals}

It must be kept in mind that there are different criteria for shoals detected by the instrument and natural ones, thus possibly generating substantial bias in further analyses. In the system used in this study the coverage is defined by the acoustic beam and the 
Table 1. List of descriptors produced by Movies-B

\begin{tabular}{|c|c|c|c|}
\hline Variables & Unit & Descriptors Name & Remarks \\
\hline Shoal No & - & Number of pings & \\
\hline No. Emis & number & Number of samples & \\
\hline No. Ech & number & day & \\
\hline dd & - & month & \\
\hline MM & - & year & \\
\hline YY & - & hour & \\
\hline $\mathrm{Hr}$ & decimal & minute & \\
\hline Min & decimal & latitude & \\
\hline Lat & decimal & longitude & \\
\hline Long & decimal & $\log$ & \\
\hline $\begin{array}{l}\text { Lm } \\
\text { Prof }\end{array}$ & $\begin{array}{l}\text { nautical mile } \\
\text { meter Dept }\end{array}$ & & \\
\hline Amin & $\begin{array}{l}\text { meter Shoal } \\
\text { mimum altiitude }\end{array}$ & & \\
\hline Pmin & $\begin{array}{l}\text { meter shoal } \\
\text { dept }\end{array}$ & & \\
\hline Arel & percent & Shoal altitude index & Arel $=100($ Amin $+\mathrm{H} / 2)$ Prof \\
\hline Lmax & m & Length of shoal & \\
\hline Hmax & m & Height of shoal & \\
\hline Elon & $\mathrm{m}$ & Elongation of shoal Elon=L/H & \\
\hline Dfrt & - & $\begin{array}{l}\text { Fractal dimension Dfrt=2(In } \\
\text { Peri/4)(In Aire) }\end{array}$ & \\
\hline Aire & $m^{2}$ & Cross-section area & \\
\hline Peri & M & Perimeter & 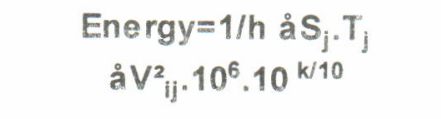 \\
\hline Energy & $m V^{2}$ & Back-scattered energy & Where $k=$ sounder constant \\
\hline
\end{tabular}

speed of the vessel. If a shoal is larger than the coverage area, then only part of the shoal will be detected by the acoustic system. In the case of shoal detection by MOVIES-B, a discontinuity that defines the border of shoal may be false, and two close shoals identified by this system may really be a single shoal. Factors generating these biases (Fréon et al., $1993 ; 1996)$ include deformation of the shoal due to avoidance to vessel passage in the near surface layer (Fréon \& Geriotto, 1988) and diel variability.

Evaluation will be focused on the possibility of the spatial gradients along longitudinal and latitudinal directions. An attempt at deeper analysis is also carried out emphasizing distribution along the "straight transect" from Karimunjawa to Matasiri Bank (legs $\mathrm{KB}, \mathrm{BM}$ and q) in comparison with south-north legs in the western, central and eastern parts of the area surveyed. Overlays of information on shoal distribution by depth and classified size with bottom con- tours are performed in two-dimensional presentations of vertical coverage, i.e. by depth and longitude.

In this part we also re-analyse shoal data using the outputs of the MOVIES system (measured in deviation, $Q d$ with unit in $m V^{2}$ ) which were played back by the acoustic team of the Pelfish Project in Jakarta. Some of these data had been analysed and presented elsewhere (Petit et al., 1995). Totals of 929 and 912 shoals in Cruises 41 and 34 (rather than the 350 and 143 shoals analysed here) were identified and extracted by performing the MOVIES system with setting thresholds defined by the team. However, these differences can be explained as follows. The MOVIES software does not automatically recognize the shoa! (as does MOVIES-B), therefore, the shoals have to be determined by matching the result of visual observations from the echogram feature (at given thresh. olds) and the values of deviation (Qd) obtained by playing back the raw data using this software. If an aggre- 


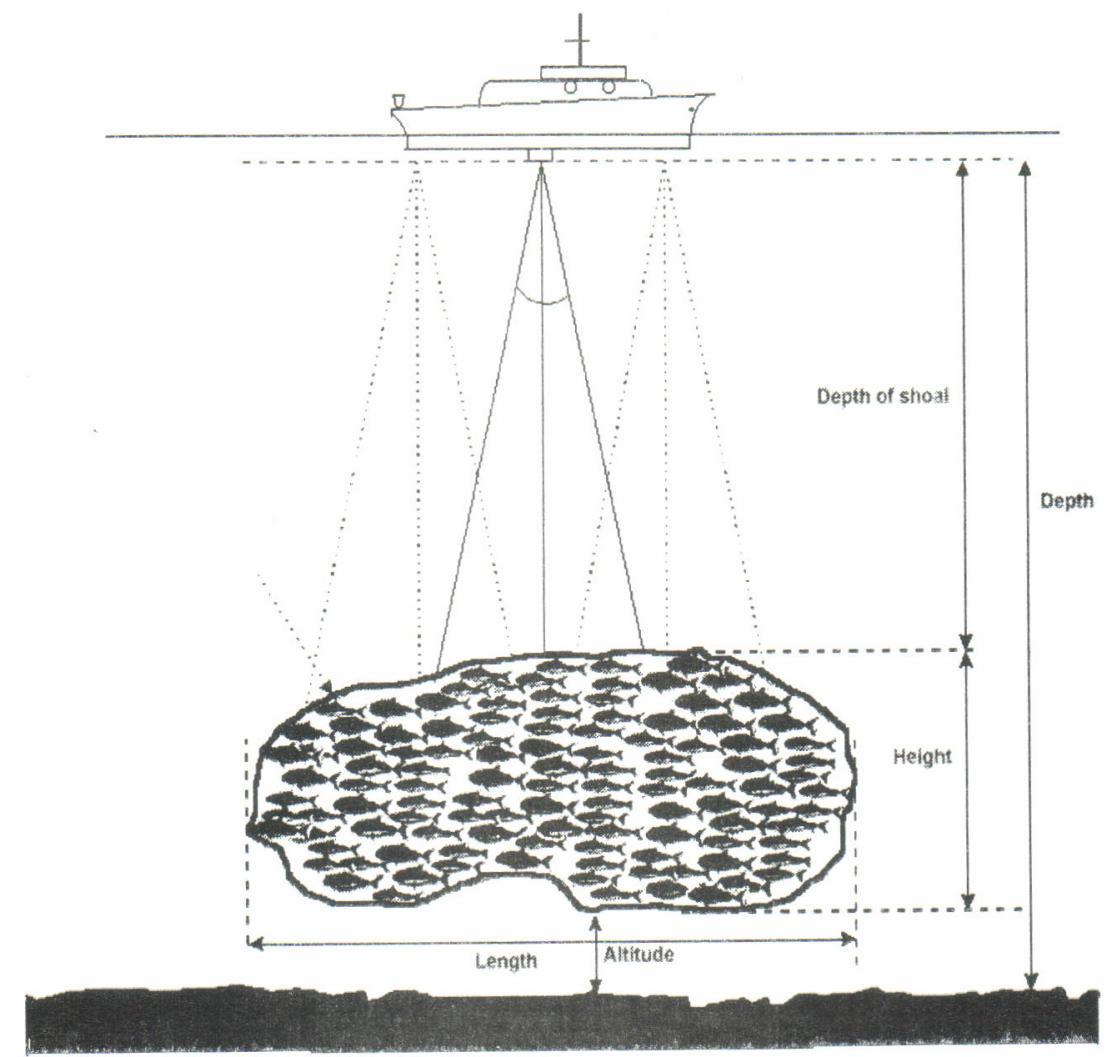

Figure 3. Morphological and spatial parameters computed by Movies-B (Diner, 1995)

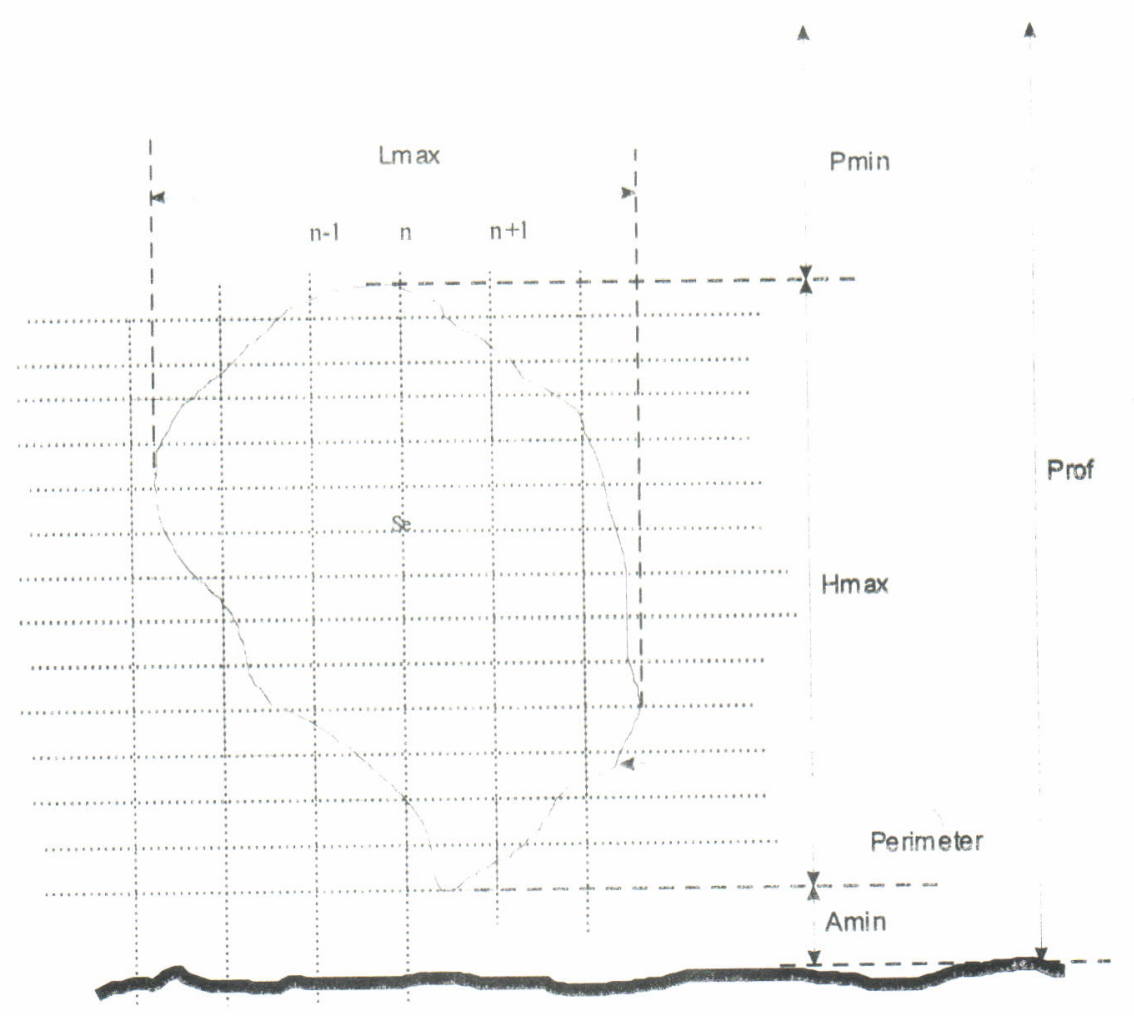

Figure 4. Definition of shoal by means of the acoustic detection (Weill et al., 1993) 
gation as marked in the echogram results in "sharp" deviation, it will be interpeted as a shoal. This manual observation resulted in shoals being identified at thrice the rate of those identifed by MOVIES-B where almost all of these shoals have $\mathrm{Qd}$ factor values more than $0.01 \mathrm{mV}^{2}$. In order to clarify the definition of measurement unit of $\mathrm{Qd}$, it should be born in mind that the value of $Q d$ is relative, of which the multiplier factor of 1000 was defined when playing back the data in order to ease scale reading of the echogram.

The number of shoals derived by this protocol decreases as the minimum value of $Q d$ rises. This simulation indicates that the minimum $Q d$ value used by this protocol is too low, and the value of $0.05-0.06$ $\mathrm{mV}^{2}$ gives results similar to those of MOVIES-B. At the $\mathrm{Qd}$ minimum criterion, the two softwares do not give the same number of shoals identified. Using MOVIES-B, we introduce a magnitude of $100 \mathrm{mV}^{2}$ (equivalent to $0.035 \mathrm{mV}^{2}$ in $\mathrm{Qd}$ ) as the minimum energy for a shoal. At minimum $\mathrm{Qd}$ of $0.04 \mathrm{mV}^{2}$ for MOVIES the number of shoals identified is still greater than those for MOVIES-B. As these softwares tend to give different results we could not compare the influence of other thresholds on the shoal identification. A comparison of the measurement values of the two softwares is beyond of the scope of this study. Despite this, the acoustic data can still be used to describe the general distribution of schooling patterns.

\section{Large scale distribution}

A general comparison of the average shoal size of the two cruises can be expected to explain seasonal distribution of the pelagic shoals. We can see that during the southeast monsoon (October), the number of shoals and their average sizes are bigger than those during the northwest monsoon (February). As shown by the summary of shoal data and the distribution along the transects, the shoals also tend to be closer to each other in the eastern part of the area (Figure 5). Gradients of shoal distribution in the west-east direction are clearly observed in the October cruise, when highly clumped shoal aggregations were frequently found in the easten part. There are three subareas where the shoal clustering formations occur close together with denser biomass; sub-area of Masalembu-Matasiri bank, sub-area extending from Kangean Island to the near continental edge of eastern part of Matasiri Bank and the coastal area in the North coast of Central Java.

Diurnal migratory behaviour occurred in most of the area covered during the two seasons. In October. a diel pattern is more apparent than in February. During the dry season (October), the fishes tend to form smaller shoals and maintain a closer distance during night-time, as indicated by the lower average value of $\mathrm{Qd}$ and smaller distances between the shoals. During the day-time, however, bigger shoals were apparently found in most of the area, but were less numerous than the smaller ones. In February no specific pattern was observed, except for some extreme values of Qd in the eastern part of the survey area (legs $n$ and $p$ ) and near coastal area in the north coast of Central Java during the February cruise

\section{Distribution in longitude}

For these analyses the same east-west transects as used in the previous part were chosen (i.e. from Karimunjawa to Matasiri Bank: legs KB, BM and $q$ with steaming distance of 440 and 331 nautical mile for cruises 41 and 34 respectively) and night and day discriminations were performed. Unfortunately the positions of the night and day-time tracks were not exactly the same and no particular track was covered repeatedly during day and night to know diurnal movements precisely. General observations can be focused on the nearest position by ignoring this difference and combining all times of observations

As shown in Figure 5, different patterns of distribution are exhibited during day and night-time, and diurnal patterns seems to be apparent, particularly in the Masalembu-Matasiri Bank. During northwest monsoon (in February), a high aggregation of shoals was observed during day and night in the sub-area between Masalembu and Matasiri Bank and the shoals tended to occupy the mid-layer during both the day and night. In the western part, the occurrence of shoals was rare and their sizes were smaller. In the other season (October), higher densities and numerous shoals were found along the transect with similar patterns of concentration (i.e. a tendency of fish to form shoals in the same longitude during the two season). During the day, denser shoals tended to occupy the near bottom layer, while in the night shoals of smaller densities were observed during the October cruise in the eastern sub-area. In February this variability was not clear, with high density shoals existing in the subarea of Masalembu-Matasiri Bank all the time at the same layer. In general, based on the evenness of shoal occurrence and the gradient of aggregation pattern in west-east direction for the two periods of the survey, we can infer that the longitude $114^{\circ} \mathrm{E}$, or the western slope of Masalembu Bank, is a particular border for a different type of shoal clustering (see also Figure 6). Petit et al. $(1995 ; 1997)$ characterized the high density shoals as "oceanic community" and the smaller ones, with a relative low density and an homogeneous geographical distribution, as "pelagic type" shoals 

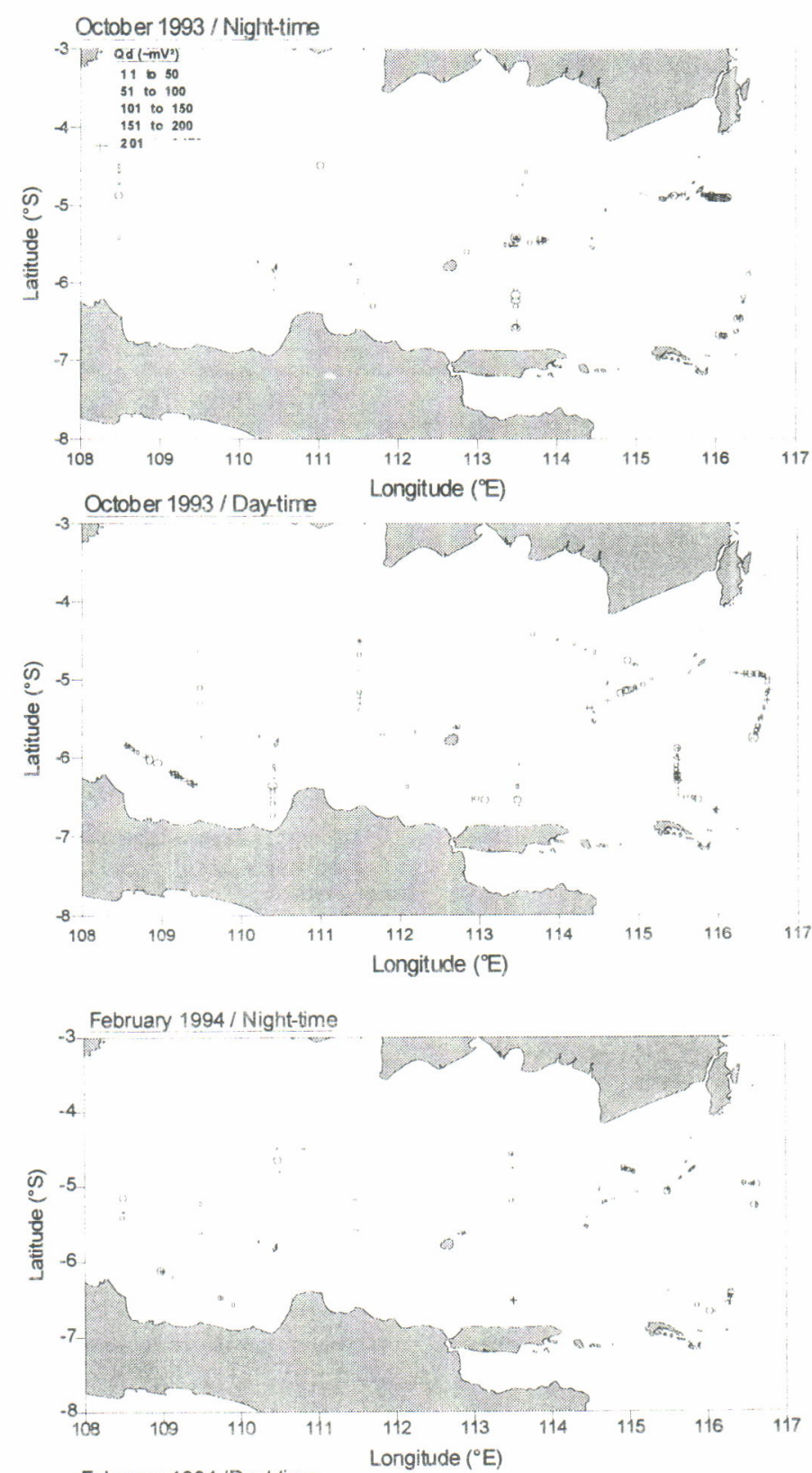

-3. February 1994 /Dayt-time
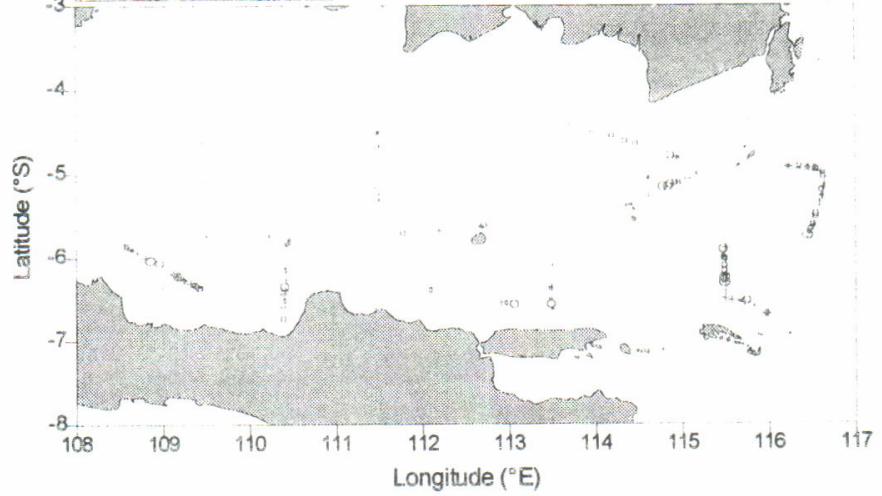

Figure 5. Shoal distribution by deviation (Qd) extracted by using MOVIES-B 


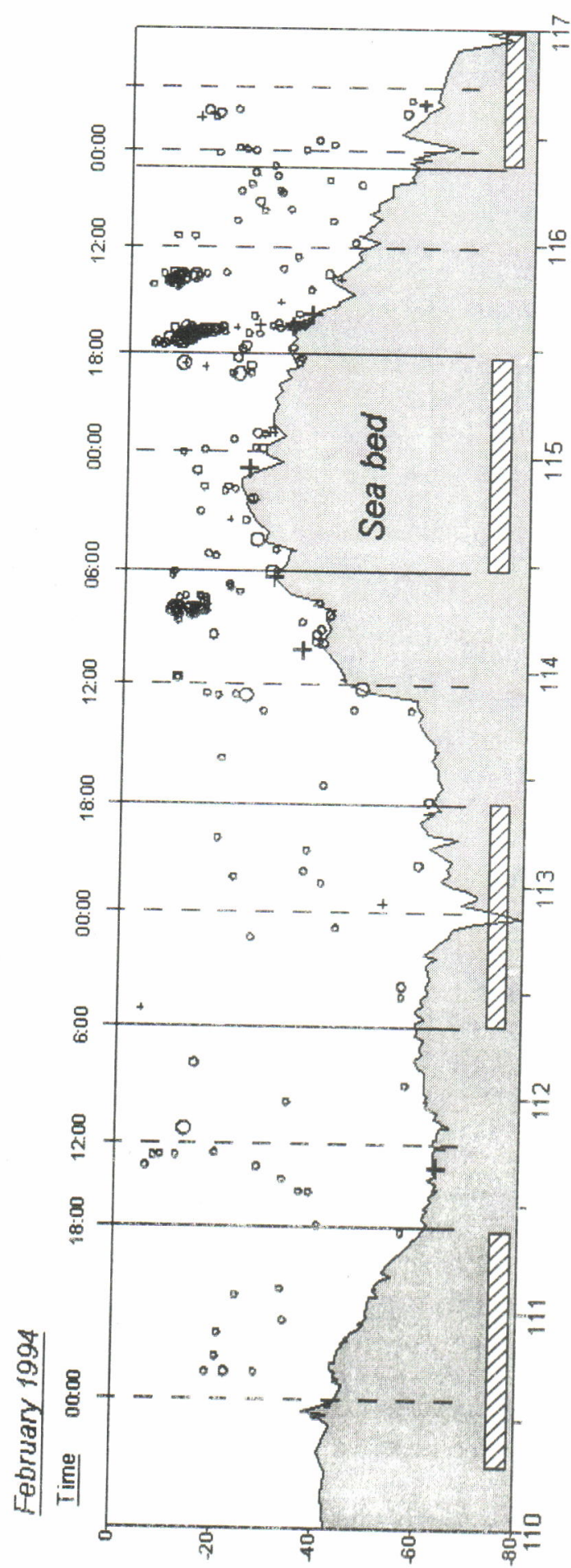

(w) 41dea

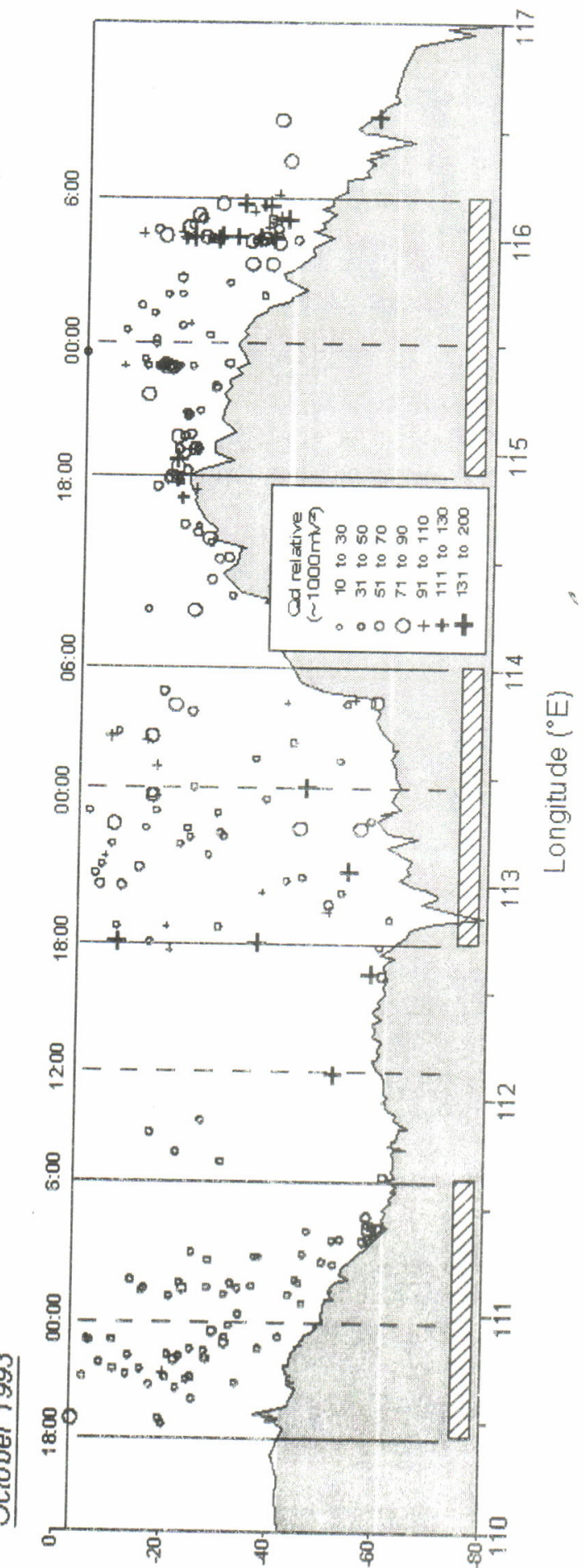

(u) प1deO

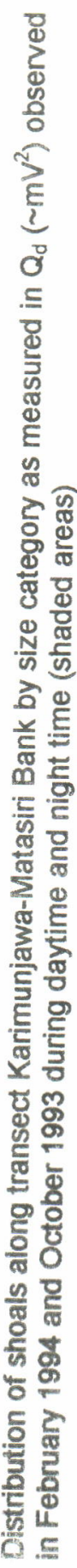

$\infty$
녹
은 


\section{Structure of acoustic shoals}

The following analyses are based on measurements or classes of descriptors produced by MOVIES-B, the descriptors being extracted from acoustic data for each shoal identified by the software. This step is aimed to evaluate the structure of the shoals in the context of spatial distribution and aggregation. We still use the same legs as previously applied for shoal data. In this study, not all of the variables produced by MOVIES-B are used, because of specific correlations between certain variables. For example, the relationship between $\mathrm{Qd}$ and Energy are completely linear. We can state that backscattering volume, Rv (in $\mathrm{dB}$ ) is proportional to the internal density of the shoal, and deviation $\mathrm{Qd}$ (in $\mathrm{mV}^{2}$ ) is proportional to the "biomass" of the shoal. In this case Rv and Qd/ Area will exhibit a logarithmic relationship. The size of the shoal is expressed as an energetic variable (i.e. biomass measured in deviation, Qd), as well as in geometric variables (i.e. length, height, perimeter and cross sectional area). The position of the shoal is defined as a vertical postion at given latitude or longitude including minimum depth (shoal depth), altitude from sea bed (altitude) and relative altitude (percentage of shoal depth to bottom depth).

In these cases, the shoal data derived from the MOVIES-B would be more explainable as these data contain more variables than those from the older version. The internal structure of a shoal can be characterized by the variability of descriptors variables (Scalabrin \& Massé, 1993).

A common ordination technique is to enable the multi-dimensional data structure to be projected in descriptor variables ( $R^{p}$ space) and in individual shoal space $\left(R^{n}\right.$ space). To do this, we emphasize the variability of the value rather than the profile structure or shape of the data. For this reason, principal component analysis (PCA) would be more appropriate than correspondence analysis to summarize the multi-dimensional data and to provide a geometric of low dimensional representation.

Figure 7 shows a two-dimensional plot of the first two principal factors. The variance explained by these components for the cruises 34 and 41 data reveals that the geometric descriptor variables are well represented, i.e. more than $50 \%$ of the total variance. High variance of some individual shoals is attributed to high observed value of certain descriptors (particularly the perimeter and length) as indicated in the $\mathrm{R}^{\mathrm{n}}$-space figures. In term of "distance" between points representing the individual shoals, a grouping "cloud" of points or shoals was evidently observed during the February cruise. In the same presentation, the data of cruise 34 seem to be more homogenous and the difference of the mean of descriptors between legs of this cruise also indicates a lower fluctuation compared with those of cruise 41 . Inspection of the positions of individual shoals belonging to these groups (during cruise 41) reveals a possible preference of the fish on specific areas (Figure 5). Unfortunately, there is no additional information available to explain this pattern. However, it is possible to speculate on two factors playing an important role in governing the shoal structure. The first factor is salinity. Higher salinity water exists in the deep layers in the western part of the area and probably in the eastern area near the continental edge as it is influenced by the waters coming from the Macassar Strait.

The group A and C (as coded as "9" shown in Figure 8 ) would be composed by the oceanic species. In this, attention can be focused on places where higher concentrations of shoals are observed over relatively short distances (as shown in energetic dimensions ( $Q d$ and $R v$ ) generated from the two softwares). The high variation of the values of descriptors between $113^{\circ}$ and $114^{\circ}$, and $116^{\circ}$ and $116^{\circ} 30^{\prime} \mathrm{E}$ in the longitudinal direction transect, and in the south of west leg (i.e. in the coastal subarea of north of Central Java) and in the northeast leg (in the near continental shelf) may not be readily ascertainable. However, many factors may determine this variation, but fishes' responses to sea-water conditions at a small-scale may be exhibited by various types of shoals with particular characteristics. An attempt to clarify the distribution can be based on the typology of the shoals.

\section{Shoal typology and stratification}

This typology will allow the classification of shoals into strata with homogenous characteristics. Each stratum should contain individuals which are relatively homogenous with respect to shoal size or morphologic dimension variables (deviation, back scattering volume, length, height, perimeter, area of shoals) and position dimension variables (altitude, altitude relative to bottom depth, and depth).

Based on these measurements, stratification can be performed by using a statistic (i.e. similarity distance) for defining homogeneity criteria. Descriptive statistical techniques may be performed emphasizing classification, and aimed to show a general clustering of the acoustic shoal to describe the spatial distribution corresponding to the co-ordinates.

For this purpose, analysis can be performed in two steps: (a) to classify each shoal into strata, and (b) to map a new variable representing these dimensions on their correponding positions. 
(1) Descriptor Space

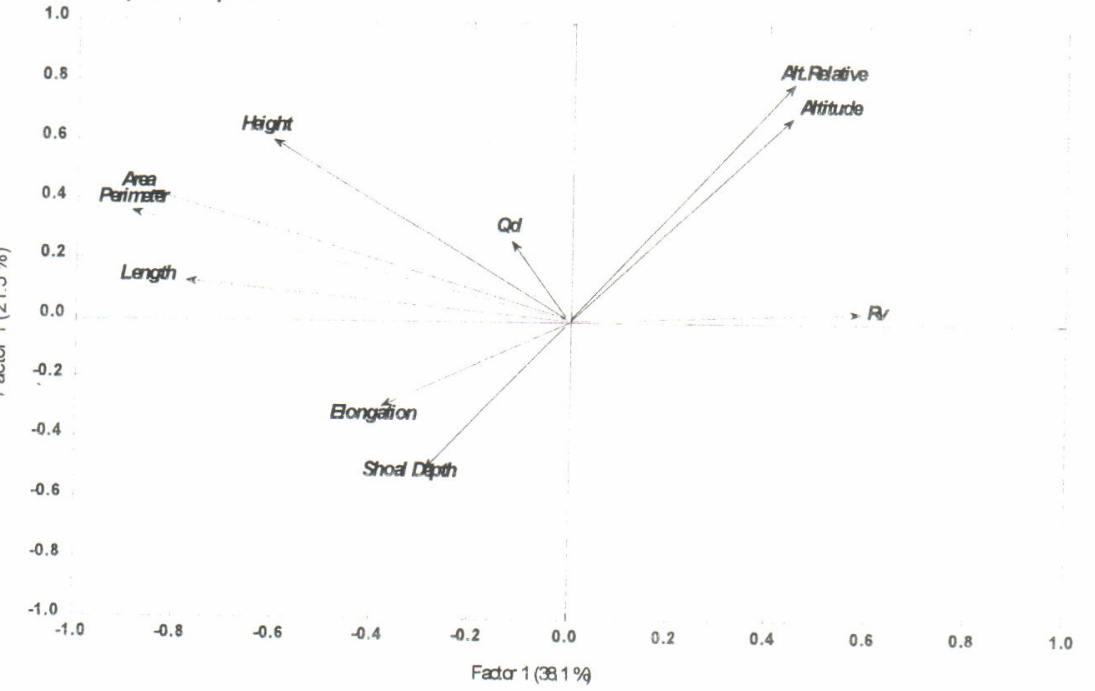

(2) Rn space

1.4

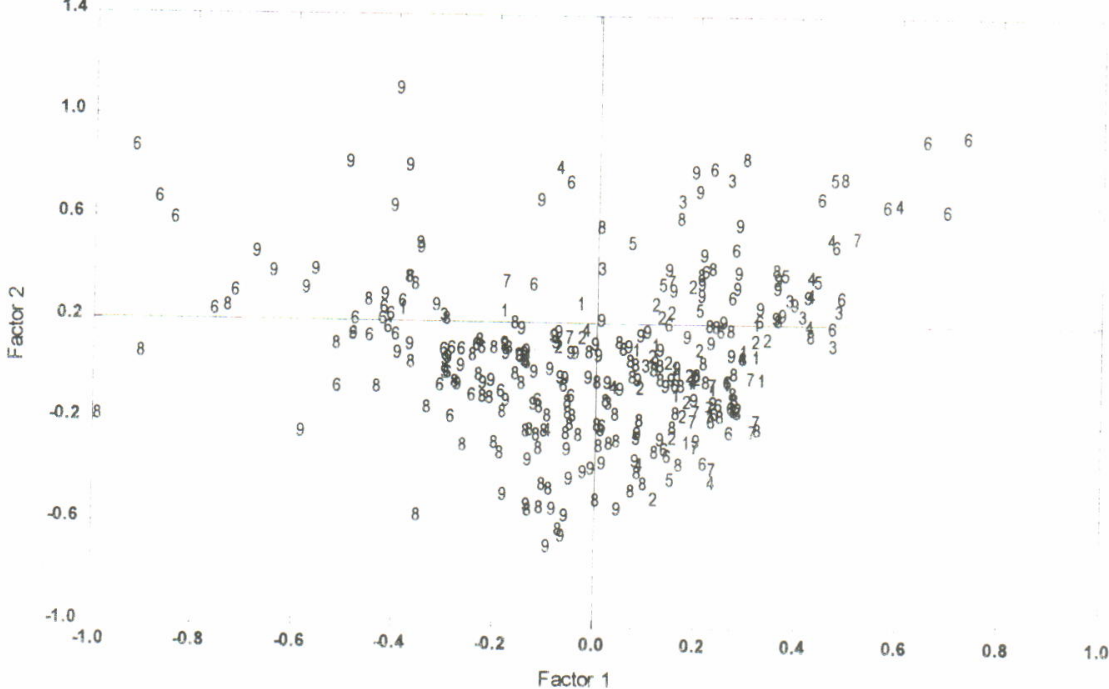

Figure 7. Cruise 34/October 1993: Plot of the first two factors derived from PCA on shoal data

(Remarks: numbers are indicating the longitude range; $1=1080 \mathrm{E}, 2=1090 \mathrm{E}, \ldots, 9=1160 \mathrm{E}$ )

\section{Classification}

This step is not specific, but means that the clustering will result in a general division of shoals into different strata with respect to the above measurements. In order to clarify further interpretation, we define only three strata of shoals, as more than this number of strata artificially produces very few individuals per group. In general, computation using the K-means method will produce clusters of greatest possible distinction based on the Euclidian distance attributed to the variables in Table 1.

However, re-filtering the shoal data is still needed to relegate the extreme and unreasonable values of $\mathrm{Qd}$ and the length of shoal due to the inability of the
MOVIES-B software to identify perfectly the shoals staying in the near bottom layer

Some shoals having these attributes are considered as out-liers and are excluded from the data input. The algorithm is to examine iteratively all shoal partitions and to select one which is the closest to the centroids being calculated as a moving average of the distance. As shown in Table 1, the size dimension appears to be the dominant variable in determining this classification. The pre-defined strata tend to correspond to their biomass (Qd) and length dimension, so that the shoals may be categorized as big, medium and small. In this paragraph we use the terminology "type 1" and "type 2" to discriminate the different strata derived from cluster analysis without specifying their characteristics. 
In attempting to observe the pattern of shoal type distribution we focus on the big shoal category. Observations on the shoal typology reveal possible zonation generated by similarity of certain shoal characters, even though this evaluation is limited by the lack of the same track observed during both day and night.

In February: there are three zones, one is in the eastern part between $115^{\circ} 30^{\prime}-117^{\circ} \mathrm{E}$, the second one is in the northern part, North of Masalembu Bank, and the third is in the middle area between $109^{\circ}$-a $113^{\circ}$ Et (Bawean Island).

In October: the first zone is in the eastern part near the continental slope, the second one is Masalembu Bank and the last one is the area extending from Matasiri to Kangean Island.
Karimunjawa Bank and in the middle of the Java Sea (see also Figure 6). The big night-shoals occupied Masalembu and Matasiri Bank, while the medium category shoals seemed to dominate the sub-areas in the North of Kangean Islands. In February, the small types sparsely occupied almost all parts of the area, with only a few big shoals found in Matasiri Bank and in the near slope to the north of the Kangean Islands.

\section{Spatial stratification}

In this part, the term of zonation and stratification should not be confused with the patchiness of shoal distribution pattern. These terms are aimed at explaining the different patterns of shoal structure at different locations in the Java Sea. In the previous analysis, description of the change of pattern by sub-areas is based on the real position of the acoustic shoals. In this part, the pattern is described by interpolation of

Table 1. Average value of shoal dimension by groups (remarks: the groups defined by K-means method)

\begin{tabular}{|c|c|c|c|c|c|c|c|c|c|c|c|}
\hline $\begin{array}{l}\text { No. of } \\
\text { shoals }\end{array}$ & Strata & $\begin{array}{l}\text { Qd } \\
\left(m V^{2}\right)\end{array}$ & $\begin{array}{l}\text { Rv } \\
\text { (dB) }\end{array}$ & $\begin{array}{l}\text { Atifude } \\
(\mathrm{m})\end{array}$ & $\begin{array}{c}\text { Shoal } \\
\text { depth }(m)\end{array}$ & $\begin{array}{c}\text { Atitude } \\
\text { relative (\%) }\end{array}$ & $\begin{array}{l}\text { Length } \\
(\mathrm{m})\end{array}$ & $\begin{array}{l}\text { Height } \\
(\mathrm{m})\end{array}$ & $\begin{array}{l}\text { Elong } \\
\text { ation }\end{array}$ & $\begin{array}{l}\text { Area } \\
\left(m^{2}\right)\end{array}$ & $\begin{array}{l}\text { Perimete } \\
\qquad r(m)\end{array}$ \\
\hline \multicolumn{12}{|c|}{ February $1994 / \mathrm{Night}$ and Day } \\
\hline 132 & 1 & 0.15 & -46.6 & 11.7 & 29.8 & 31.1 & 12.2 & 2.7 & 5.6 & 15 & 38 \\
\hline 17 & 2 & 0.29 & -51.1 & 6.3 & 45.2 & 20.6 & 31.2 & 6.5 & 6.6 & 77 & 193 \\
\hline 6 & 3 & 0.66 & -52.1 & 13.8 & 46 & 34.1 & 71.6 & 10.2 & 8.2 & 290 & 608 \\
\hline \multicolumn{12}{|c|}{ February 1994 / Day } \\
\hline 63 & 1 & 0.15 & -46.2 & 10.9 & 26.4 & 31.9 & 11.1 & 2.6 & 5.4 & 13 & 32 \\
\hline 17 & 2 & 0.37 & -49.1 & 8.2 & 27.6 & 31.8 & 26 & 4.7 & 6.9 & 54 & 102 \\
\hline 2 & 3 & 0.59 & -51.9 & 15.7 & 65.7 & 22.6 & 54 & 10.1 & 5.4 & 258 & 463 \\
\hline \multicolumn{12}{|c|}{ February 1994 / Night } \\
\hline 60 & 1 & 0.12 & -46.7 & 12.6 & 35.2 & 28.8 & 11.6 & 2.7 & 5.5 & 15 & 40 \\
\hline 9 & 2 & 0.27 & -52.3 & 7.5 & 51.8 & 19.3 & 43.4 & 6.5 & 9.5 & 97 & 260 \\
\hline 3 & 3 & 0.69 & -52.8 & 16.2 & 35.8 & 49.2 & 74.4 & 12.1 & 6.1 & 334 & 768 \\
\hline \multicolumn{12}{|c|}{ October Night and Day } \\
\hline 70 & 1 & 0.17 & -54.4 & 5.3 & 38.7 & 17.4 & 41 & 6.8 & 7 & 89 & 257 \\
\hline 258 & 2 & 0.144 & -49.4 & 12.1 & 38.8 & 26.6 & 17.1 & 3.8 & 5.4 & 29 & 65 \\
\hline 11 & 3 & 0.322 & -54.9 & 6 & 44.6 & 19 & 82.2 & 11.3 & 8.7 & 289 & 664 \\
\hline \multicolumn{12}{|c|}{ October 1993 / Night } \\
\hline 58 & 1 & 0.123 & -54.9 & 5.3 & 38.4 & 17.5 & 43.5 & 6.7 & 7.4 & 88 & 272 \\
\hline 140 & 2 & 0.205 & -50.4 & 12.2 & 38.7 & 26.8 & 19.6 & 3.6 & 6.2 & 30 & 77 \\
\hline 10 & 3 & 0.304 & -55.4 & 4.6 & 47 & 16 & 88.3 & 10.8 & 9.4 & 305 & 681 \\
\hline \multicolumn{12}{|c|}{ October 1993 / Day } \\
\hline 84 & 1 & 0.18 & -47.2 & 10.6 & 35.3 & 25.4 & 12.1 & 3 & 4.7 & 20 & 36 \\
\hline 44 & 2 & 0.22 & -50.7 & 13.6 & 47.7 & 27.4 & 20.8 & 6.4 & 4.2 & 52 & 98 \\
\hline 8 & 3 & 1.03 & -48.5 & 10.5 & 31 & 30.6 & 31.9 & 10.7 & 3.4 & 153 & 255 \\
\hline
\end{tabular}

In term of patchiness in the occurrence of big shoals, a tendency towards aggregation is evidently observed-shoals coded as 9 in the cloud of points $A$, (Figure 8). In October, big shoals found in the near slopes during the day time, in the North of Madura, in generalized variables by performing ordinary krigging to create graphical presentation.

Since the natural shoal characteristics can be assumed to be represented by those acoustic shoals, mapping the acoustic shoal variables on the actual 
chart may spatially describe their stratification. It will, however, face the problem of defining the appropriate variables in conjunction with their position and coordinates. For this reason a canonical correlation analysis will be peformed, which gives a new variable (canonical scores) representing both sets of variables with a mathematical solution of maximizing the correlation between the first variable set (size dimension variables) and the second variable set (position and co-ordinate variables).

In this part we perform two steps of analysis. The first is to determine the important variable that characterize the acoustic shoal and the second to deter- mine a possible zonation derived from the canonical variate.

\section{Size and position variables relationship}

Two sets of variables are used in the analysis, namely a position dimension set composed of longitude, latitude, depth, altitude, relative altitude of shoals and bottom depth; and a size dimension set consisting of $\mathrm{Qd}, \mathrm{Rv}$, height, length, perimeter and area of shoals. One would expect that the canonical variates would represent combinations of variables.

High canonical correlations between the position dimension and the size dimension set of variables appear to be significant for further interpretation, as

(1) Descriptor Space

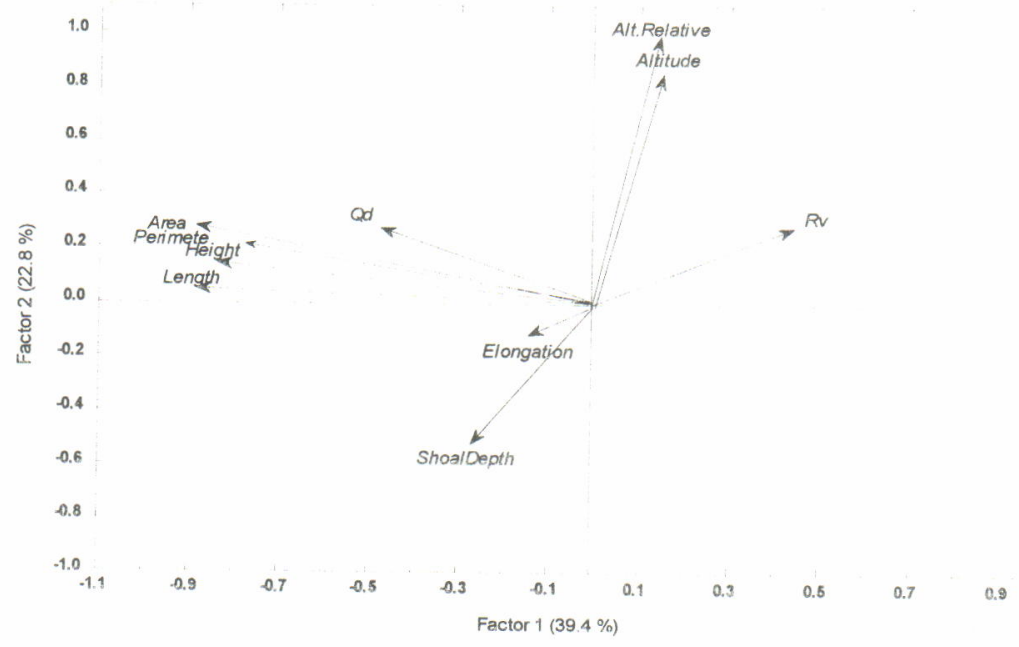

(2) $R^{n}$ space

$$
1.0
$$
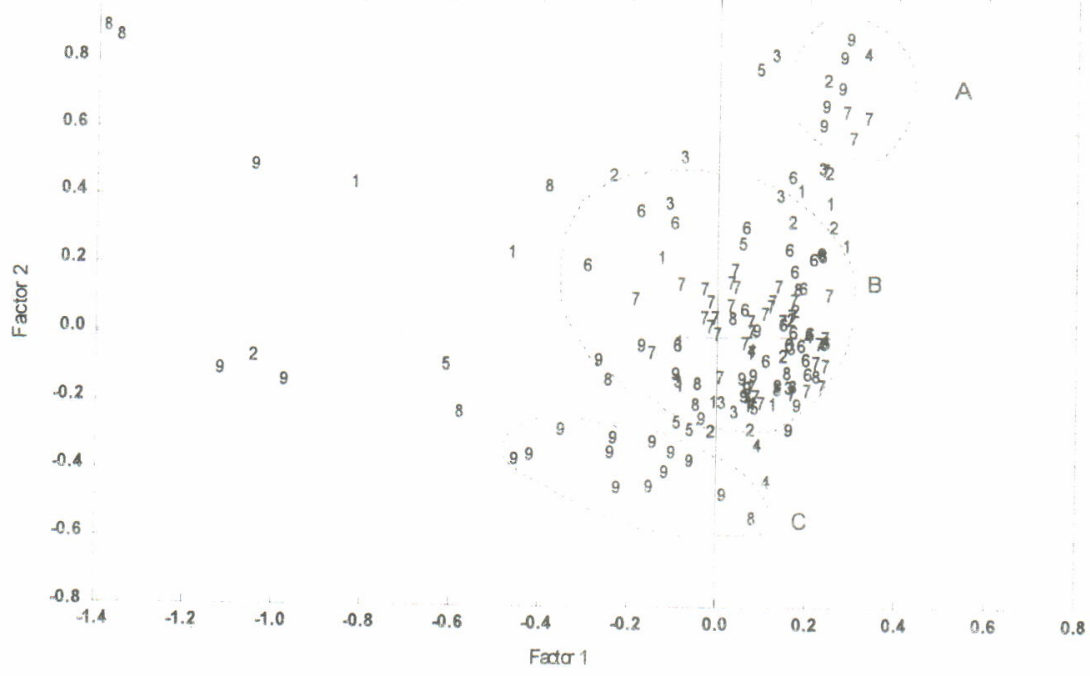

Figure 8. Cruise 41/February 1994: Plot of the first two factors derived from PCA on shoal data (Remarks: numbers are indicating the longitude range; $1=108^{\circ} \mathrm{E}, 9=116^{\circ} \mathrm{E}$ ) 
these correlations account for a large proportion of the variability in the data ( $r$ 's are greater than 0.85 for all shoal types) (Table 2). However, in this analysis, we use the first two roots for describing the variability. The height of the shoal contributes to the first canonical variate (also to the second one for some shoal types), while the second variates tend to correspond to $\mathrm{Qd}$ and Rv. On the other hand, the bottom depth and shoal altitude significantly explain the variability of the position set of variables

These variables dominate the contribution to the total explained variance for the size dimension set of variables. Height of shoal and bottom depth can be called influence variables in determining the factor structure of shoal data, but, it is not necessary to conclude also that these measurements are the most important in describing the shoal structure.

\section{Zonation}

Following Gittins (1986), plotting the canonical scores of the size dimension set of variables onto a chart with respect to their latitude and longitude may describe the nature of the spatial distribution. This procedure was applied to different types of shoals (Figure 9) and times of observations (Figure 10), in order to reduce the variation of the data. These plots intuitively describe the spatial distribution of the shoals with respect to size dimension variables in an analogous way to the zonation of the comunity structure.

As shown in the figures, a possible zonation of shoal types generated by size descriptors seems to appear for all seasons in the Java Sea. This zonation pattern may be sufficient evidence to classify this area according to morphological factors, as well as to the position set of variables. The high contribution of shoal height and back-scattering volume (Rv) to the canonical factor also demonstrate a similar pattern for the presentation.

Three zones are clearly identified, i.e. the western (north of Central Java), the middle (KarimunjawaBawean Island) and the eastern parts (Masalembu, Matasiri, and Kangean Islands). Attention should be paid to the time of observation, as the size dimension variables may vary with time. For example, in October, most of medium shoals were observed during the night-time, while small shoals were equally common by day or night.

In general, this mapping would reflect a subdivision of the Java Sea into three parts, with the middle area frequently represented by a consistent blank area showing few shoals, especially for February. Different times of observation may also obscure the limit of zonation. The next step is to confirm the limit of zo- nation which can be performed by defining a border in between $113-114^{\circ} \mathrm{E}$ segment (in this case we use $113^{\circ} 30^{\prime} \mathrm{E}$ ) based on the previous findings. Putting different labels for the shoals detected in the western and eastern part of this border, the superimposed plots of the first two components (individual or shoals space on size dimension variable space) reveal a clearer separation of another type of shoal (Figure 11). We can then contrast the shoaling patterns of the two sides sub-areas during October, where two groups of points tend to separate and correspond to the eastern part of the border (labeled as "1") and western area. In terms of Euclidian distance, we can infer that "eastern" shoals are characterized by their length dimension (perimeter, length, height, area), while the "western" shoals tend to be influenced by position dimension (altitude and relative altitude ). In fact, the mean values of length dimension of the eastern shoals are greater than those of the western ones, as well as their variances (as indicated in the graph by longer vectors of length dimension variables).

\section{Spatial distribution}

The spatial distribution evaluated in term of the number of shoals and their size (Qd) per unit distance or segment (for example in one degree) in the eastwest transect gives an indication of different aggregations of shoals in the eastern and western parts of the area. The straight line transect of KarimunjawaMatasiri Bank is more representative of the direction of fish movement being followed by the fishermen, while the influence of morphological features maybe more important in the sub-area located near to Kalimantan and Java-Madura coast, and in the near continental slope

Detailed inspection on these points of the southnorth transects, reveals a possible high aggregation of schooling composed of coastal and migrant spe. cies in the western part (in the near coastline of Central Java) and near the continental break in the eastern part (leg $p)$. These are in accordance with the findings of Petit et al. (1995; 1997) who named these aggregations as coastal and oceanic pelagic communities. However, these phenomena do not stand alone and should be seen in relation to biological factors (species composition and size) and variabiity of the Java Sea as induced by seasonal climatic factors.

A question relating to different longitudinal preference of fish shoals is crucial, especially in relation to migration, gradient of body size, salinity distribution and water exchange in the whole Java Sea. This brings us to the problem in relation to species identification of the existing shoals or clusters, as fishing samples 
(1) First canonical component of size descriptors set

Shoal type 1 (big shoal)

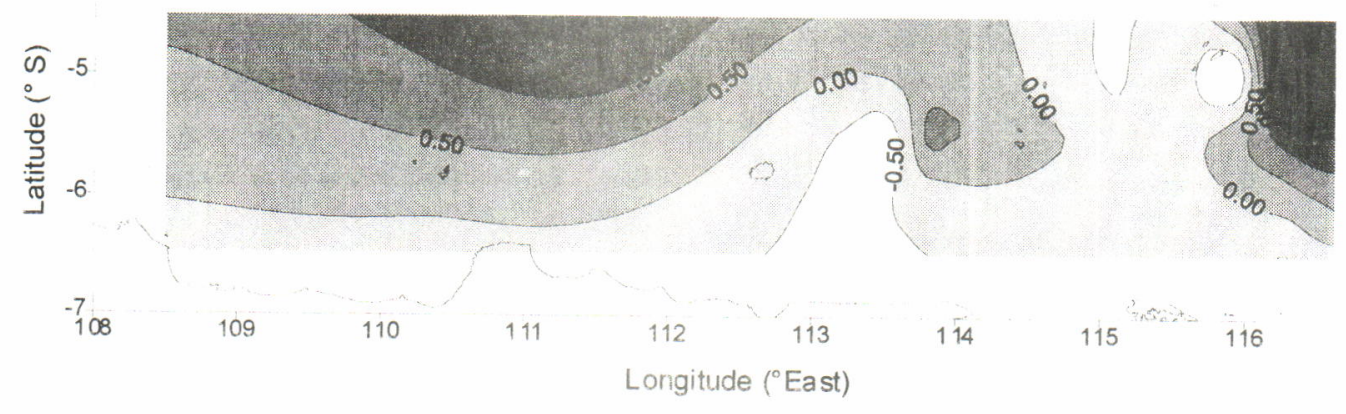

-4 Shoal type 2 (medium shoa)

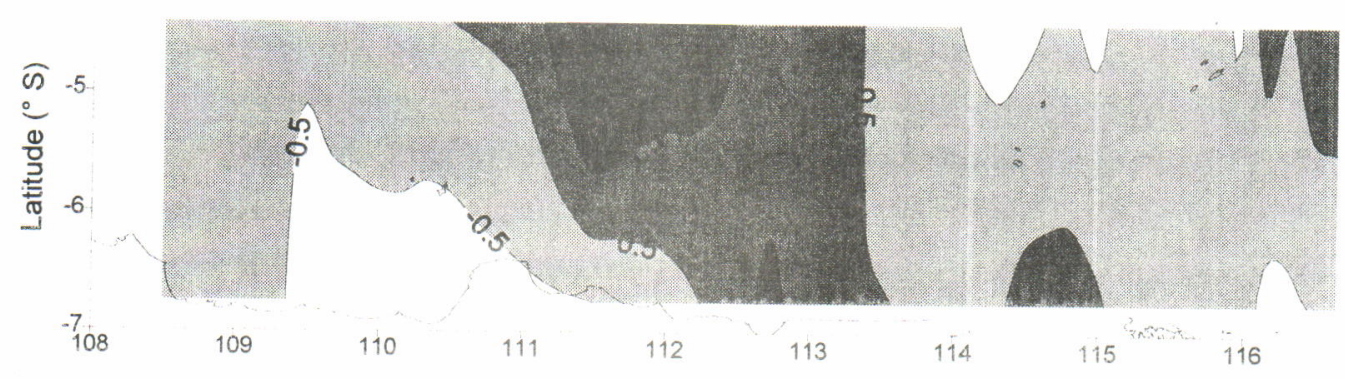

(2) Shoal height variable
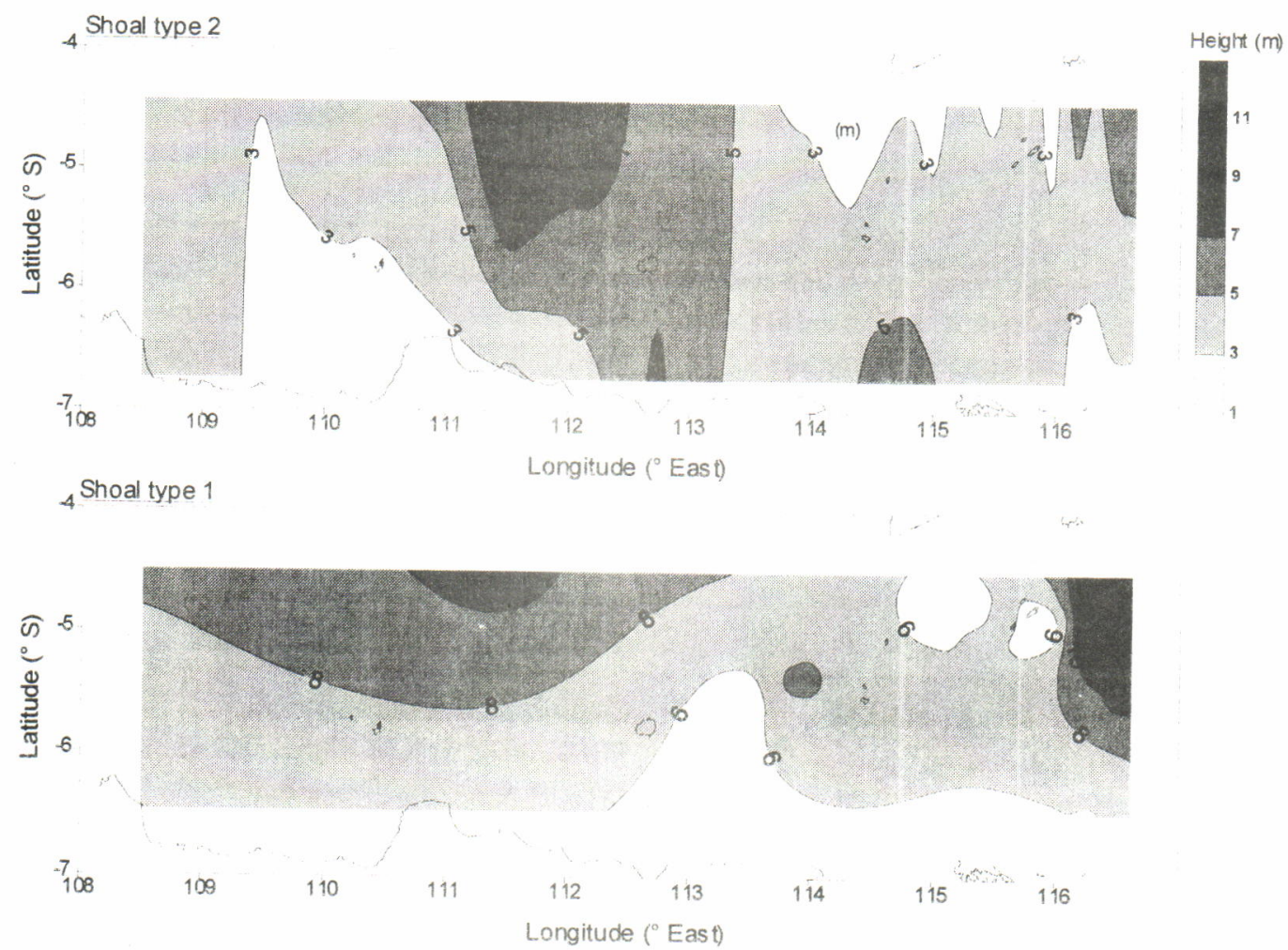

Figure 9. Contour of first canonical component of size descriptors set (1) and height of shoals (2) of Cruise 34 as being superimposed on the chart 
Table 2. Summary of canonical correlation analysis by types of shoal

(a) Summary

October 1993

\begin{tabular}{|c|c|c|c|c|}
\hline \multicolumn{3}{|c|}{ Shoal type 1} & \multicolumn{2}{|c|}{ Shoal type 2} \\
\hline$\chi_{(36)}^{2}=22.25$ & onical R: $0.97 p=0.00$ & & $\chi_{(36)}^{2}=661$ Canonical $R$ & $0.94 p=0.00$ \\
\hline Items & Position Dimension & Size Dimension & Position Dimension & Size Dimension \\
\hline $\begin{array}{l}\text { Variance } \\
\text { extracted }\end{array}$ & $100 \%$ & $100 \%$ & $100 \%$ & $100 \%$ \\
\hline Total redun-dancy & $14.00 \%$ & $35.00 \%$ & $11.40 \%$ & $41.10 \%$ \\
\hline Variables: & & & & \\
\hline 1 & LATITUDE & QD & LATITUDE & QD \\
\hline 2 & LONGITUDE & RV & LONGITUDE & RV \\
\hline 3 & BOTTOM DEPTH & LENGTH & BOTTOM DEPTH & LENGTH \\
\hline 4 & ALTITUDE & HEIGHT & AL.TITUDE & HEIGHT \\
\hline 5 & SHOAL DEPTH & AREA & SHOAL DEPTH & AREA \\
\hline 6 & ALTITUDE RELATIVE & PERIMETER & ALTITUDE RELATIVE & PERIMETER \\
\hline \multicolumn{5}{|l|}{ February 1994} \\
\hline \multicolumn{3}{|c|}{ Shoal type 1} & \multicolumn{2}{|c|}{ Shoal type 2} \\
\hline$\chi_{(36)}^{2}=210$ & onical R: $0.856 \quad p=0.00$ & & $\chi_{(36)}^{2}=50.7$ Canonical & $R: 0.89 \quad p=0.05$ \\
\hline Items & Position Dimension & Size Dimension & Position Dimension & Size Dimension \\
\hline $\begin{array}{l}\text { Variance } \\
\text { extracted }\end{array}$ & $100 \%$ & $100 \%$ & $100 \%$ & $100 \%$ \\
\hline $\begin{array}{l}\text { Total redundancy } \\
\text { Variables: }\end{array}$ & $8.30 \%$ & $31.00 \%$ & $39.50 \%$ & $47.90 \%$ \\
\hline 1 & LATITUDE & QD & LATITUDE & QD \\
\hline 2 & LONGITUDE & RV & LONGITUDE & RV \\
\hline 3 & BOTTOM DEPTH & LENGTH & BOTTOM DEPTH & LENGTH \\
\hline 4 & AL.TITUDE & HEIGHT & ALTITUDE & HEIGHT \\
\hline 5 & SHOAL DEPTH & AREA & SHOAL DEPTH & AREA \\
\hline 6 & ALTITUDE RELATIVE & PERIMETER & ALTITUDE RELATIVE & PERIMETER \\
\hline
\end{tabular}

(b) Canonical weight

October 1993

\begin{tabular}{|c|c|c|c|c|c|c|c|c|c|}
\hline \multicolumn{5}{|c|}{ Canonical Weight of Position set variables } & \multicolumn{5}{|c|}{ Canonical Weight of Size dimension set variables } \\
\hline Items & Shoal & type 2 & Shoalt & type 1 & Hems & Shos & Type 2 & Sho & altype 1 \\
\hline Variables & Root 1 & Root 2 & Root 1 & Root 2 & Variables & Root 1 & Root 2 & Root 1 & Root 2 \\
\hline LATTTUDE & 0.01 & -0.8 & 0.01 & 1.48 & QD & 0.03 & -0.27 & 0.18 & 1.16 \\
\hline LONGTUDE & 0.01 & -0.23 & -0.02 & -0.79 & RV & -0.05 & 0.88 & -0.14 & -1.72 \\
\hline BOTTOM DEPTH & 9.13 & -0.24 & 4.87 & 2.57 & LENGTH & 0.03 & 0.18 & -0.07 & 0.01 \\
\hline ALTITUDE & -5.26 & 0.14 & -2.83 & -1.07 & HEIGHT & 1.01 & 0.87 & 0.93 & -0.21 \\
\hline SHOAL DEPTH & -9.8 & -0.48 & -4.26 & -1.6 & AREA & -0.04 & -0.42 & -0.02 & -0.1 \\
\hline ALTITUDE RELATIVE & 0.02 & 0.4 & 1.11 & -0.63 & PERIMETER & -0.02 & -0.43 & 0.04 & 0.43 \\
\hline \multicolumn{10}{|l|}{ February 1994} \\
\hline \multicolumn{5}{|c|}{ Canonical Weight of Position set variables } & \multicolumn{5}{|c|}{ Canonical Weight of Size dimension set variables } \\
\hline Items & Shoal & type 1 & Shoal & type 2 & Items & & al type1 & Sho & lype 2 \\
\hline Variables & Root 1 & Root 2 & Root 1 & Root 2 & Variables & Root 1 & Root 2 & Root 1 & Root 2 \\
\hline LATTTUDE & 0.07 & 0.48 & -0.01 & -2.12 & QD & 0.06 & 0.1 & 0.29 & 2.04 \\
\hline LONGITUDE & 0.03 & 0.63 & 0.26 & 1.48 & RV & -0.08 & 0.26 & 0.04 & -0.08 \\
\hline BOTTOM DEPTH & -12.25 & -0.72 & -7.11 & -5.02 & LENGTH & 0.08 & 0.08 & 0.12 & -1.67 \\
\hline ALTITUDE & 7.22 & -0.69 & 1.38 & -0.25 & HEIGHT & -0.89 & 0.38 & -0.8 & -1.77 \\
\hline SHOAL DEPTH & 12.19 & 1.62 & 6.77 & 3.19 & AREA & -0.19 & -1.88 & -1 & -2.77 \\
\hline ALTITUDE RELATIVE & -0.28 & 1.5 & -0.45 & 1.61 & PERIMETER & -0.06 & 1.74 & 0.59 & 4.51 \\
\hline
\end{tabular}




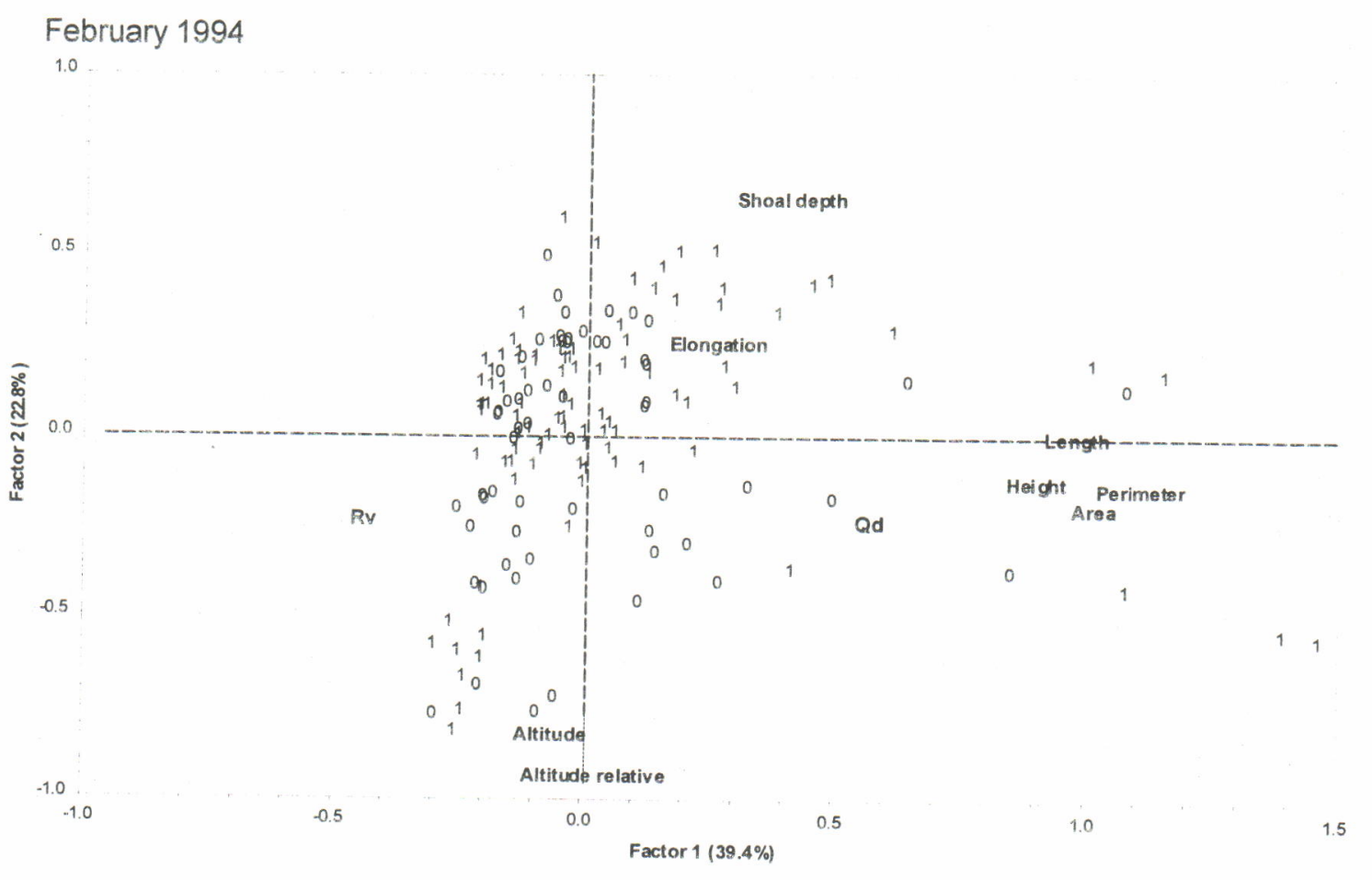

\section{October 1993}

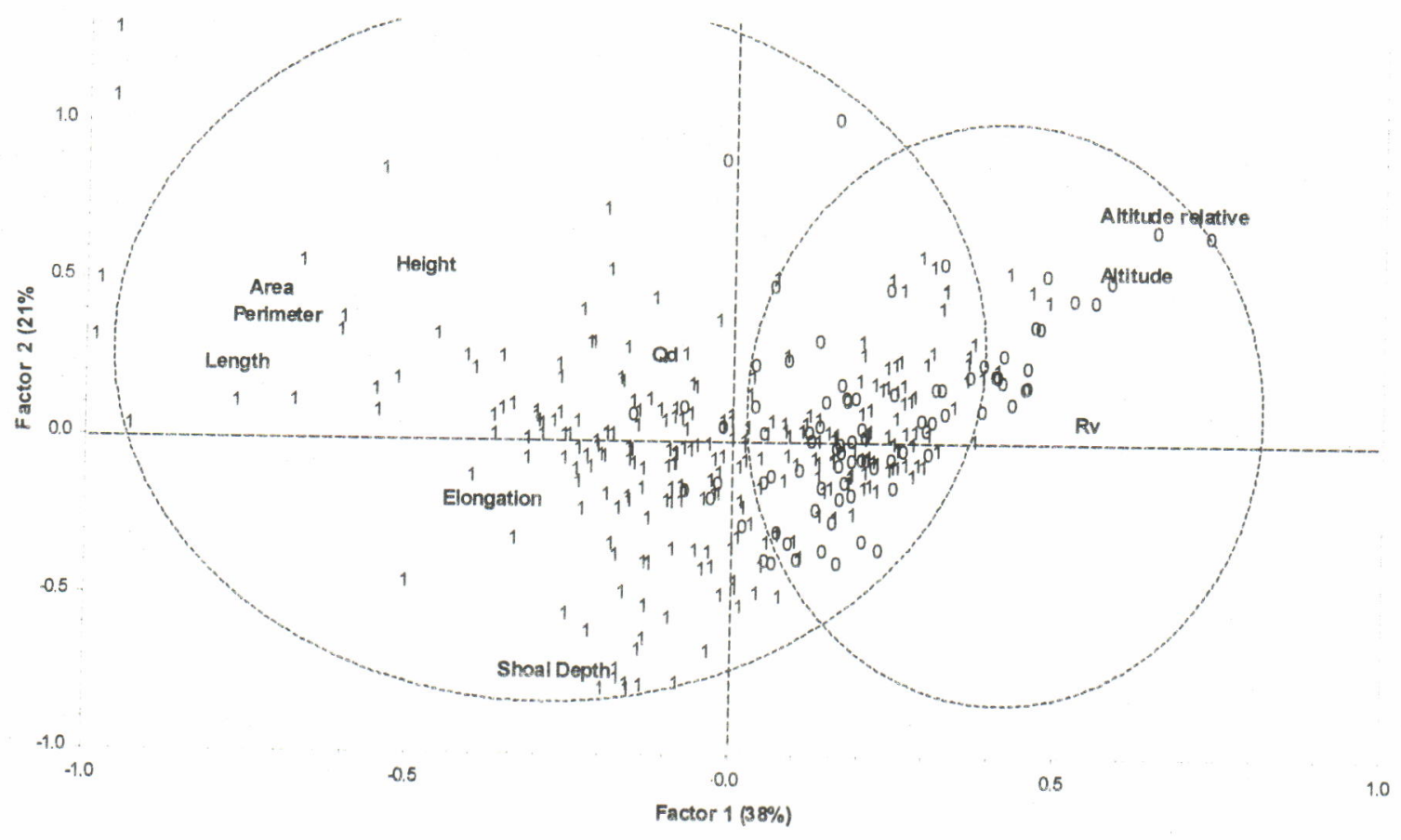

Figure 11. Biplot of the first two components derived from PCA (Remarks: 1's and 0's denote shoals occupying East and West parts of $113^{\circ} 30^{\prime} \mathrm{E}$ border, respectively, dotted-circle lines are fitted by eye to indicate grouping of points)

an assemblage of coastal species occupies the near coastline area extending from north of Cirebon to the Karimunjawa Island.
In February the pattern is not as clear as of October. Following salinity gradients, the oceanic species tend to stay in the western part (Sadhotomo, inpress), 
while the neritic species (perhaps the coastal ones too) prefer to occupy the eastern area from MasalembuMatasiri Banks In this case, we can deduce that some oceanic species may stay in the western part where they have been considered by previous studies as another population entering the Java Sea from the Sunda Strait during the rainy season (Hardenberg, 1938; Widodo, 1988). Until now, there has been no confirmation of the hyphothesis on the origin of this stock.

Based on an assumption that different patterns of behaviour relate to the different species forming the shoal, evaluations can be attempted for different patterns of aggregation in the sub-areas. Shoal clustering in denser concentrations is observed in the eastern part of the Java Sea (included the near continental slope and certain places beyond of the fishing zones) during the northwest and southeast monsoons. In certain places, such as the Masalembu-Matasiri Bank, different patterns are clearly displayed during February and October. Also, as indicated by different patiern in diurnal variability in some areas during the two seasons, we can suggest that different species make up the shoal. We can infer that a typical oceanic species would be more likely to undertake migration following a diurnal rhythmic in high light transmission water, as indicated by the shoal occupy the Masalembu-Matasiri Bank during October, while less structured vertical movements would be exhibited by the non-oceanic species during rainy season in the same place.

In February, this sub-area (the MasalembuMatasiri Bank) will be favourable for neritic or coastal species and young fishes, as it is of considerably lower salinity in the eastern part of the area surveyed (Sadhotomo \& Potier, 1995). Land mass impact on the eastern area as induced by heavy rainfall in Kalimantan during December - January would enrich these waters with nutrients from the coastal area. Also the current (flowing west to east) would not create a clear border of water mass gradient (contrary to those during the southeast monsoon in October). This latter condition causes discontuinities of water mass with some dispersed patchiness in the eastern area of the Java Sea (Wyrtki, 1956). A more heterogeneous distribution of species and size naturally exists in this area (Sadhotomo \& Potier, 1995), coincidentally, with more variation of migratory behaviour of shoals and target strength distribution are exhibited. Following this phenomenon, it can be suggested that the shoals during the rainy are less structured and composed of more species than those during October

However, the above evaluation is in relation to a small scale area, i.e the area covered by the cruise tracts. In the larger area, it is interesting to consider migration and its influence on fish distribution in relation to the features of acoustic populations inside the Java Sea.

The migratory scheme relates to the concept of the Java Sea populations. Two types of migrations may be considered, i.e. seasonal and internal migrations. The seasonal migration the movement of a big mass of fish from other areas (the South China Sea, Makasar Strait, and Flores Sea). During the northwest monsoon, the neritic fishes (mainly D. russellii) enter the Java Sea from the western and northern areas (the South China Sea) as planktonic and nectonic stages (Sadhotomo, 1998) During the southeast monsoon, the direction of migratory activity reverses (from east to west), and the migrants entering the Java Sea during this season are much more important than those of the southeast monsoon. At the beginning of this season, the young fish that previously entered the Java Sea as planktonic stages probably mix with new recruits coming from the eastern archipelago and Makasar Strait

From the end of the southeast monsoon (i.e. October - November)), a reciprocal movement to the east occurs, with the new immigrants coming from the eastern archipelago. This movement is marked by a shift of the aggregations along an axis from Karimunjawa Island to Matasiri Island. These movement are defined as an internal migration and it has been briefly discussed elsewhere (Sadhotomo, inpress). During the northwest monsoon, this migration is continued, with the fishes moving in three directions: to the east (Flores Sea), northeast (southern part of Makasar Strait) and southeast direction. A small part of them migrates to the west as far as the north of Sunda Strait where the salinity of the area is still more than $31 \%$. Petit et al. (1997) indicated that the nocturnal behaviour of the shoals along the north coast of West Java observed in April - May 1995 was different from those off the Central and East Java coast. The diel movement pattern of these shoals was very similar to those of the shoals located in the sub-area of Matasiri Bank in October 1993. Genetic evaluation of D. russellii specimens collected in April 1995 (Perrin, 1998) also confirmed this possibility. In previous studies (e.g. Hardenberg, 1938; Widodo, 1988), this stock was usually regarded originating from the Indian Ocean population entering the Java Sea during northwest season. Consequently, the orientation of the pelagic community distribution extends from the middle of the Java Sea to eastern areas. 


\section{CONCLUSION}

\section{Spatial distribution pattern}

Shoal clusters tend to occupy the shallow bank in the certain subareas, mostly concentrated in the sub area between Masalembu-Matasisri Bank and the north coast of Central Java. During the Northwest monsoon, aggregation of the group of neritic species (dominated by $D$. russellii) occupy the western part of the Java Sea, in the higher salinity layer. The origin of these stocks is probably the western population or a mixture of two populations, or the rest of the Java Sea stock undergoing the migration to the higher salinity waters area, such as the Sunda Strait or the Indian Ocean. In the eastern part, spesific aggregation is obvious, particularly in the sub-area extending from Matasiri Bank to southern most part of the Makasar Strait. In the recent years, this migratory phenomenon to the western ecological area has become less important, and not easy to detect, as their shoal cluster size has been significantly reduced due to high exploitation in the eastern part.

\section{Stratification of the pelagic community}

Two zones with different types of aggregation can be recognized in term of their spatial distribution, with a "border" splitting them around west of Bawean Island. These zones represent the different types of aggregation reflecting group of fish of particular communities as indicated by catch composititon.

For the sake of clarification, we may synthesise the above explanation as the following points. The migration schemes described above may endanger stratification of the pelagic community into three parts during the two seasons:

- During northwest monsoon, the western zone would be composed of a mix of migrant and resident coastal species: during the opposite season, it would consist of young migrant fish and the coastal species.

- In the eastern zone, near the continental slope, the aggregation of the migrant or oceanic species seems to be more important, as shown by the large number of shoals clustering in this sub-area, during the two seasons

- In the central part, the coastal species dominate the community during northwest monsoon. During the dry season (southeast monsoon), the contribution of young migrant species to the community is notable.

\section{REFERENCES}

Anon. 1972. Echo Integrator's Manual. SIMRAD QM $S I M R A D, 2^{\text {nd }}$. Edition, March 1972. 574E pp.
Arnaud, S. 1996. Le chinchard, Decapterus macrosoma, poisson pélagique de Mer de java, un exemple d'espèce marine génétiquement structurée. Mem. DEA. USTL-ENSAM. Montpellier. $21 \mathrm{pp}$.

Burczynski, J. 1982. Introduction to the use of sonar systems for estimating biomass. FAO. Fish. Tech. Pap. 191, Rev. 1. 89 pp.

Diner, N. 1995. Utilsation de l'acoustique dans la recherche halieutique. In Diner et Marchand (eds). Acoustique et pêche maritime. IFREMER.

Foote, K.G. 1979. On representing the length dependence of acoustic target strength of fish. J. Fish. Res. Board Can. 36:1490-1496.

Foote, K. G. 1980a. Effect of fish behaviour on echo en. ergy: the need for measurement of orientation distribution. J. CIEM. 39(2):193-201.

Foote, K.G. 1980b. Angular measues of dorsal aspect target strength function of fish. FisDir. Skr. Ser. HavUnders. 17:49-70.

Foote, K.G. and Ona, E. 1985.a. Swimbladder cross sections and acoustic target strengths of 13 pollack and 2 saithe. FiskDir. Skr. HavUnders. 18: 1-57.

Foote, K.G. and Ona, E. 1985b. Tilt angle of schooling penned saithe. ICES. C.M. 1985/B:26.

Fréon, P., Gerlotto, F. and Soria, M. 1990. Evaluation of the influence of vessel noise on fish distribution as observed using alternatively motor and sails aboard s survey vessel. Com. to ICES statutory meeting, Bergen, oct. 1990. CM/B:55. 15 pp.

Fréon, P., Gerlotto, F. and Soria, M. 1996. Diel variability of school structure with special référence to transition periods. ICES J. Mar. Sci. 53: 459-464.

Fréon, P., Gerlotto, F. and Misund, O.A. 1993. Conse. quences of fish behaviour for stock assessment. ICES mar. Sci. Symp. 196: 190-195.

Fréon, P., El Khattabi, M., Mendoza, J. and Guzman, R. 1997. Unexpected reproductive strategy of Sardinella aurita off the coast of Venezuela. Marine Biology. 128 : 363-372

Gerlotto, F and Marchal, E. 1987. The concept of Acoustics Populations: its use for analysing the result of acoustic cruises. Inter. Symp. Fish. Acoust., June 2226, 1987, Seattle Washington, USA. 30 pp.

Gerlotto, F. 1993. Identification and spatial stratification of tropical fish concentration using acoustic populations. Aquat. Living Resour. 6: 243-254.

Gerlotto, F. and Fréon, P. 1988. Influence of the structure and behaviour of fish school on acoustic assessment. ICES. CM. 1988/B:53. 28 pp.

Gerlotto, F. and Fréon, P. 1990. Review of avoidance reactions of tropical fish to a survey vessel. ICES/FAST Working group meeting. Rostock, April 1990. 10 pp.

Gittins, R. 1986. Canonical Analysis. A review with application to ecology. Springer-Verlag. Berlin.

Greene, C.H, Wiebe, P.H. and Zamon, J.E. 1994. Acoustic visualization of patch dynamics in oceanic ecosystems. Oceanography. 7(1). $12 \mathrm{pp}$. 
Hardenberg, J.D.F. 1938. Preliminary report on a migra tion of fish in the Java Sea. Treubia, Deel 16, Afl. 2: 295-300.

MacLennan, D. N. and Simmonds, E. John. (1992). Fisheries Acoustics. Chapman \& Hall, London. 325 pp

Maravelias, C.D., Reid, D.G., Simmods, E.J. and Haralabous, J. 1996. Spatial analysis and mapping of acoustic survey data in the presence of high local variability: geostatistical application to North Sea herring (Clupea harengus). Can. J. Fish. Aquat. Sci. 53: 1497-1505

Perrin, C. 1998. Phylogénie de l'ADN mitochondrial, structure géographique et reconstruction de l'histoire évolutive des populations du complexes d'espèce Decapterus cf. russelli dans le sud-est asiatique. Mem. DEA. Univ. Mediterranee Aix-Marseille II. ORSTOM/lab. Génome et Populations, CNRS UPR $9060.43 \mathrm{pp}$

Petit, D., Cotel, P. and Nugroho, D. 1997. Densities and behaviour of pelagic fish population along the Java and Sumatra coast in wet season. Proceeding of Acoustics Seminar Akustikan 2. EU-AARDORSTOM.: 91-106

Petit, D., Gerlotto, F.and Petitgas, P. 1995. Data stratification and pelagic fish density evaluation in the Java Sea. The Fourth Asian Fishery Forum. Beijing, Oct. 1995.

Pileou, E.C. 1977. Mathemathical Ecology. Wiley, N.Y

Potier, M. 1998. Pêcherie de layang et senneurs semiindustriel javanaise: Perspective historique et approche système. Thèse de doctorat. Univ. Montpellier II. 300 pp

Radakov, D.V. 1973. Schooling in the ecology of fish. John Wiley \& Son. (Israel Translation serie). 173 pp.

Sadhotomo. B. Inpress. Pola migrasi dan populasi ikan layang (Decapterus russellii dan D. Macrosoma) di Laut Jawa:sebuah hipotesis. $12 \mathrm{pp}$.
Sadhotomo. B. and Potier. M. 1995. Exploratory scheme for the recruitment and migration of the main pelagic species. In M. Potier and S. Nurhakim (eds). Seminar on the Biology, Dynamics and Exploitations (BIODYNEX). Java Sea Pelagic Fishery Assessment Project.: 155-168.

Sainsbury, K.J. 1982. The ecological basis of tropical fisheries management. In Pauly, D. and G.I. Murphy (eds). Theory and management of tropical fisheries. ICLARM/CSIRO Conf. PrOC.

Scalabrin, C and Massé, J. 1993. Acoustic detection of the spatial and temporal distribution of fish shoal in the Bay of Biscay. Aquat. Living Resour. 6: 269-283.

Scalabrin, C. 1997. Identification Acousique des Espèces Pélagique a Partir d'attributes Discriminants des bancs de Poissons Monospecifiques. Thése doctorat. Université de Bretagne Occidèntale. Ecole doctorale des science de la mer. $244 \mathrm{pp}$.

Simmonds E.J., Williamson, N., Gerlotto, F. and Aglen, A. 1992. Acoustic survey design and analysis procedures: a comprenhensive review of good practice. ICES Coop. Res. Rep.: 187-127.

Swartzman, G. 1997. Analysis of summer distribution of fish schools in the Pacific Eastern Boundary Current. ICES. J. Mar. Sci. 54: 105-116.

Weill, A., Scalabrin, C and Diner, N. 1993. MOVIES-B: an acoustic detection description software. Aplication to shoal species' classification. Aquat. Living Resour. 6: $255-267$

Widodo, J. 1988. Population Dynamics and Management of "ikan layang", Scad Mackerel, Decapterus spp. (Pisces: Carangidae) in the Java Sea. Ph.D thesis. University of Washington, Seattle. $150 \mathrm{pp}$.

Wyrtki, K. 1956. Monthly charts of sea surface salinity in Indoesian and adjacent waters. J. CIEM, 21: 268279. 